\title{
Particulate Air Pollution and Osteoporosis: A Systematic Review
}

\author{
Kok-Lun Pang (ID \\ Sophia Ogechi Ekeuku \\ Kok-Yong Chin
}

Department of Pharmacology, Faculty of Medicine, Universiti Kebangsaan Malaysia, Cheras, 56000, Kuala Lumpur, Malaysia
Correspondence: Kok-Yong Chin Department of Pharmacology, Faculty of Medicine, Universiti Kebangsaan Malaysia, Level 17, Preclinical Building, Jalan Yaacob Latif, Bandar Tun Razak, Cheras, Kuala Lumpur, 56000, Malaysia Tel +60391459573

Email chinkokyong@ppukm.ukm.edu.my
Abstract: Air pollution is associated with inflammation and oxidative stress, which predispose to several chronic diseases in human. Emerging evidence suggests that the severity and progression of osteoporosis are directly associated with inflammation induced by air pollutants like particulate matter (PM). This systematic review examined the relationship between $\mathrm{PM}$ and bone health or fractures. A comprehensive literature search was conducted from January until February 2021 using the PubMed, Scopus, Web of Science, Google Scholar and Cochrane Library databases. Human cross-sectional, cohort and case-control studies were considered. Of the 1500 papers identified, 14 articles were included based on the inclusion and exclusion criteria. The air pollution index investigated by most studies were $\mathrm{PM}_{2.5}$ and $\mathrm{PM}_{10}$. Current studies demonstrated inconsistent associations between PM and osteoporosis risk or fractures, which may partly due to the heterogeneity in subjects' characteristics, study design and analysis. In conclusion, there is an inconclusive relationship between osteoporosis risk and fracture and PM exposures which require further validation.

Keywords: particulate matter, $\mathrm{PM}_{1}, \mathrm{PM}_{2.5}, \mathrm{PM}_{10}$, bone mineral density, fracture

\section{Introduction}

Air pollution is a critical environmental and health issue in both developing and developed countries. According to the World Health Organization (WHO) statistics in 2016 , around $91 \%$ of the world's population was living with poor air quality. ${ }^{1}$ Air pollution is closely associated with the incidence of pulmonary and non-pulmonary diseases, including metabolic disorders, cardiovascular diseases, central nervous system diseases and cancer. ${ }^{2-7}$ Recently studies also showed that air pollution predisposed the public to a higher risk of breast cancer and childhood leukaemia, apart from lung cancer. ${ }^{8,9}$ Besides, air pollution is estimated to contribute to 7 million deaths worldwide in 2016 . $^{1}$

Air pollutants can be categorised into gaseous or solid type. The common examples of gaseous pollutant are ammonia, nitrogen dioxide $\left(\mathrm{NO}_{2}\right)$, carbon monoxide $(\mathrm{CO})$, sulphur dioxide $\left(\mathrm{SO}_{2}\right)$, tropospheric or ground-level ozone $\left(\mathrm{O}_{3}\right)$ and volatile organic compounds. ${ }^{7,10,11}$ Particulate matter (PM) is the sum of heterogeneous solid air pollutants, comprising water, dust and particles. The composition of PM is highly diverse, which is usually made up of acids, water droplets, elemental carbon (black carbon), organic carbon, polycyclic aromatic hydrocarbons (PAHs), metal dust, geographical mineral dust, and nitrate or sulphate compounds. ${ }^{10,12-14}$ The classification of PM is based on its aerodynamic diameter but not its composition, wherein the particles with diameter $<10 \mu \mathrm{m}$ are grouped as $\mathrm{PM}_{10},<2.5 \mu \mathrm{m}$ as $\mathrm{PM}_{2.5}$ 
and $<1 \mu \mathrm{m}$ as $\mathrm{PM}_{1} \cdot{ }^{10}$ Ultrafine particles with aerodynamic diameter $<0.2 \mu \mathrm{m}^{15-17}$ or $\leq 0.1 \mu \mathrm{m}^{18,19}$ are also being investigated but not as common as other PM species, probably due to the limitation in detection technology. These PMs are produced mainly from human activities, such as vehicle emission, coal or biomass combustion and high-temperature industrial works (manufacturing, mining, and agricultural activities). ${ }^{10,11,20}$

The negative effects of air pollution are partly attributed to PM. $^{21}$ Short-term exposure to PM could lead to respiratory discomfort, airway inflammation, lung damages and cardiovascular disorders. ${ }^{22-24}$ Chronic exposure to PM is strongly associated with cardiopulmonary diseases, neurological disorders, cancer formation and increased mortality. ${ }^{25-28} \mathrm{PM}_{10}$ is deposited mainly on the head or nose area, with a slight deposition in the upper respiratory tracts. $\mathrm{PM}_{1}$ and $\mathrm{PM}_{2.5}$ can reach the deeper lung area, including alveoli and terminal bronchioles. $^{15,29-31}$ Subsequently, these fine particles could cross the alveolar barrier, enter the systemic circulation and reach several extrapulmonary organs. ${ }^{15}$ Mechanistically, PM could induce oxidative and inflammatory damages on respiratory tracts via mitogen-activated protein kinase and Toll-like receptor signalling pathway. $^{32-34}$ Additionally, $\mathrm{PM}_{2.5}$ and its component, PAHs, also possess genotoxic, mutagenic and clastogenic effects, contributing to its cancer induction properties. $^{35-37}$

Osteoporosis is a chronic age-related disease of the skeletal system associated with changes in endocrine, metabolic and mechanical factors. ${ }^{38,39}$ According to the National Health and Nutrition Examination Survey 2013-2014, nearly $6-11 \%$ of adults age $\geq 50$ years in the United States were osteoporotic. ${ }^{40,41}$ Osteoporosis affects mainly the elderly in both sexes, but women have a 4-time higher risk due to lower peak bone mass and the rapid decline of bone mass during menopause. ${ }^{42}$ Fragility or atraumatic fractures are the major contributors to osteoporosis-related comorbidity and mortality. ${ }^{43}$ Bone mass, measured as bone mineral content (BMC) or bone mineral density (BMD), is the surrogate indicators of bone strength. Osteoporosis is defined as a BMD value 2.5 standard deviations or more below the average value for young adult (T-score $\leq-2.5$ ) at the spine, hip or midradius. $^{44,45} \mathrm{WHO}^{45}$ and the International Osteoporosis Foundation $^{46}$ recommended using dual-energy X-ray absorptiometry (DXA) to measure the BMD for the diagnosis of osteoporosis. Quantitative ultrasound (QUS) is an alternative bone health screening technology. It is noninvasive, radiation-free and highly portable, and correlated well with DXA measurement. ${ }^{4,48}$

Some of the fixed and modifiable risk factors of osteoporosis include sex (female), old age, ethnicity, low body mass index (BMI), menopause, low physical activity, malnutrition, use of glucocorticoid, smoking, alcohol consumption and chronic diseases like diabetes and chronic kidney disease (CKD). ${ }^{49}$ The previously neglected role of pollution, like air pollution, as a risk factor of osteoporosis, is gaining attention in the recent 5 years. ${ }^{50,51}$ Several molecular mechanisms were postulated in explaining the association between PM and osteoporosis risk/fracture (reviewed in Prada et al. ${ }^{52}$ ). Several preclinical and epidemiological studies reported the pro-inflammatory properties of PM by increasing the inflammatory cells and acute response protein level and inducing inflammatory-related diseases like airway inflammation, cardiovascular diseases and arthritis. ${ }^{2,53-62}$ The upregulated inflammatory cytokines, including tumour necrosis factor- $\alpha$, interleukin- $1 \beta$, interleukin-6 and granulocyte-macrophage colony-stimulating factor, are osteoclastogenic and could stimulate bone resorption. ${ }^{63-66}$ Moreover, $\mathrm{PM}_{2.5}$ and $\mathrm{PM}_{10}$ exposures were significantly associated with serum receptor activator of nuclear factor-kappa B ligand level, suggesting their osteoclastogenic properties. ${ }^{53}$

Furthermore, PM exposure has been linked with vitamin D deficiency (reviewed in Afsar et $\mathrm{al}^{67}$ ). PM exposure was positively associated with kidney diseases and negatively associated with kidney function in converting the inactive 25-hydroxyvitamin $\mathrm{D}$ to biologically active 1,25 dihydroxyvitamin D. ${ }^{68-70}$ Additionally, PM components like metal dust are nephrotoxic. ${ }^{52}$ Moreover, PM also reduces the cutaneous vitamin $\mathrm{D}$ biosynthesis in populations with normal kidney function ${ }^{71}$ by reducing the surface solar $^{72}$ and ultraviolet radiation. ${ }^{73}$ Epidemiology studies reported lower serum vitamin D levels among healthy women, adolescents and children from the polluted area. $^{74-76}$ Additionally, PM components like PAHs were also reported to increase vitamin $\mathrm{D}$ catabolism. ${ }^{77}$ Nevertheless, the causal relationship between PM and vitamin $\mathrm{D}$ level is not yet confirmed.

To the best of our knowledge, a systematic review that summarises the relationship between PM and bone health or fractures is not available. Therefore, this systematic review aims to summarise the relationship between PM and bone health or fracture in the human population. 


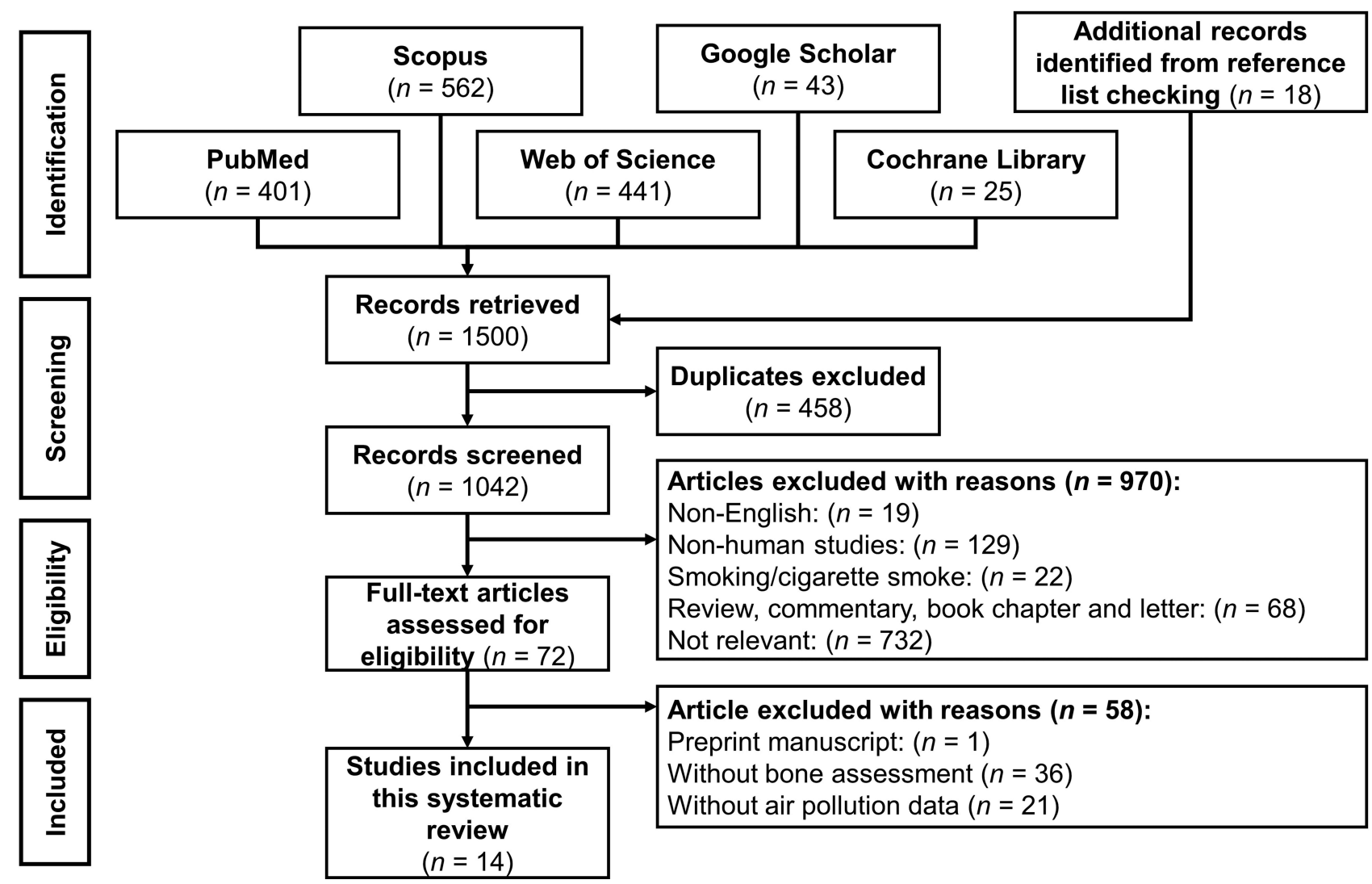

Figure I PRISMA flow chart of the systematic literature search.

Notes: PRISMA figure adapted from Moher D, Liberati A, Tetzlaff J, et al. Preferred reporting items for systematic reviews and meta-analyses: the PRISMA statement. BMJ. 2009;339:b2535. ${ }^{78}$ Creative Commons.

\section{Materials and Methods}

\section{Literature Search Strategies}

This systematic review was conducted according to the Preferred Reporting Items for Systematic Reviews and Meta-Analyses (PRISMA) guidelines and checklist. ${ }^{78} \mathrm{We}$ conducted an electronic search using five databases, including PubMed, Scopus, Web of Science, Google Scholar and Cochrane Library from January to February 2021. The following search string was used: (1) (osteoporosis OR bone OR fracture OR "X-ray absorptiometry") AND (2) ("air pollution" OR "particulate matter" OR PM2.5 OR PM10). A manual search was performed to retrieve additional records from the reference list of included studies or review papers. The detailed search strategy is provided in Supplementary Table S2. The PRISMA checklist is included as Supplementary Table S1.

\section{Eligibility Criteria and Study Selection}

We included cross-sectional, case-control, longitudinal/prospective and retrospective cohorts that reported the relationship between air pollutants, primarily particulate matter, and bone health, osteoporotic risk or fractures published within 30 years, from 1990 to 2021. We excluded studies that were (1) only available in abstract form; (2) not written in English; (3) books, book chapters, reviews, meta-analysis, conference/proceeding papers, letter to editor, and commentary; (4) pollutants or PM from smoking, cigarette smoke and tobacco; (5) no PM measurement; or (6) without bone mass assessment. The PRISMA flow chart that summarises the records identification, screening, eligibility, and inclusion of articles, are shown in Figure 1.

\section{Study Extraction}

Two reviewers (K.-L.P. and S.O.E) independently extracted the data from each article into an extraction table, firstly by referring to the title and abstract, followed by a full-text screening. Discussions with the third reviewer (K.-Y.C.) were held if there was any disagreement in the inclusion of an article. Table 1 shows the data retrieve from the articles, including the name of the first author, year of publication, year of subject recruitment/ study period, study location, study design, number of subjects, PM assessment, bone health, osteoporosis or fracture assessment and outcomes. 


\begin{tabular}{|c|c|c|c|c|c|}
\hline & $\overline{\underline{\underline{m}}}$ & $\infty$ & r & 0 & $\infty$ \\
\hline & 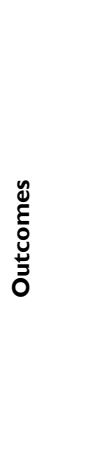 & 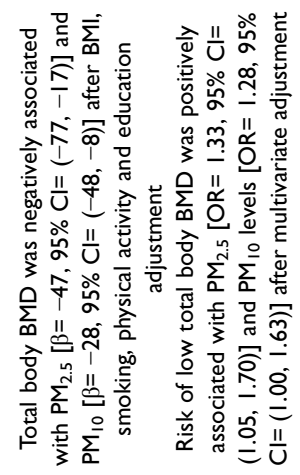 & 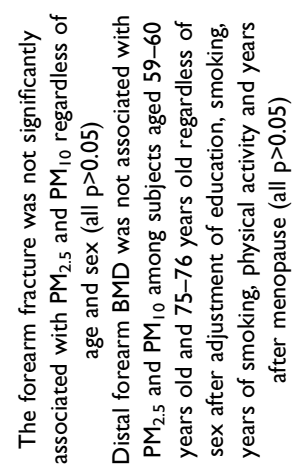 & 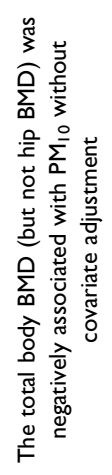 & 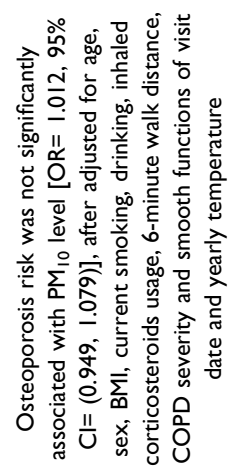 \\
\hline & 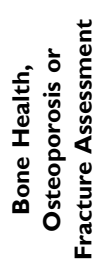 & 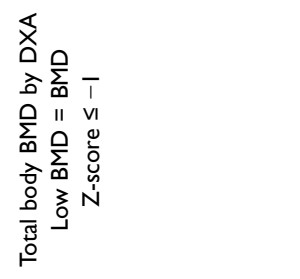 & 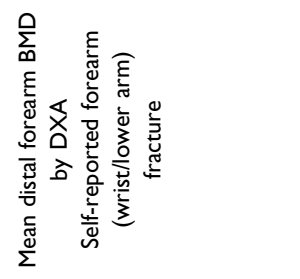 & 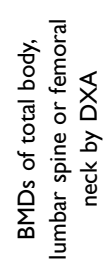 & 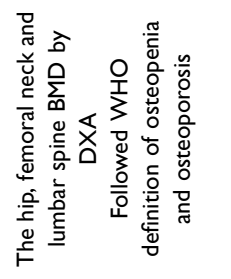 \\
\hline 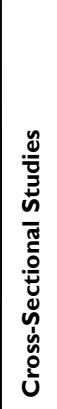 & 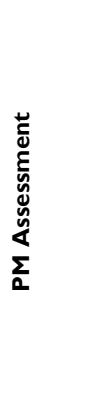 & 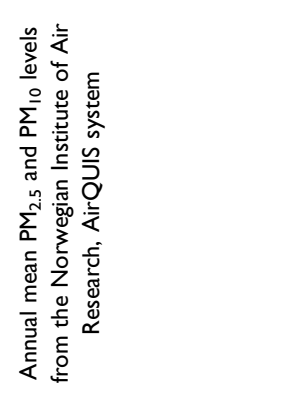 & 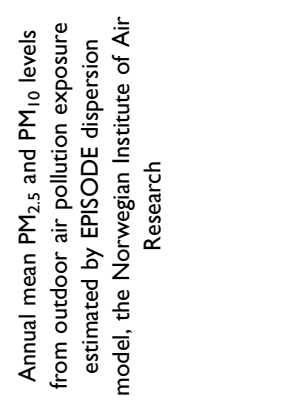 & 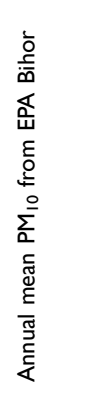 & 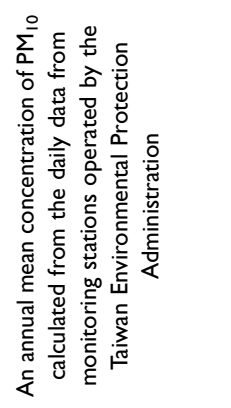 \\
\hline & 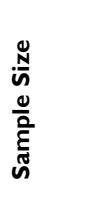 & 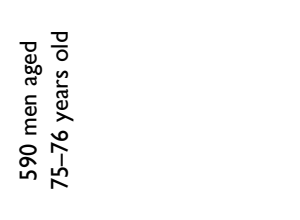 & 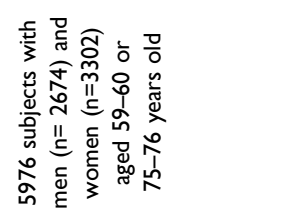 & 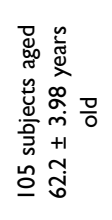 & 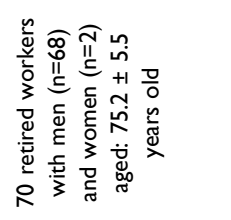 \\
\hline & 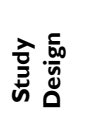 & 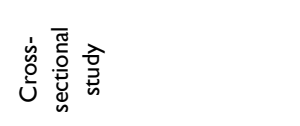 & 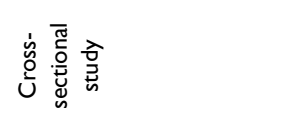 & 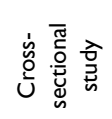 & 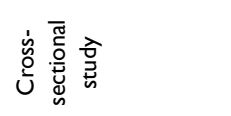 \\
\hline & 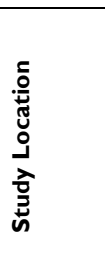 & 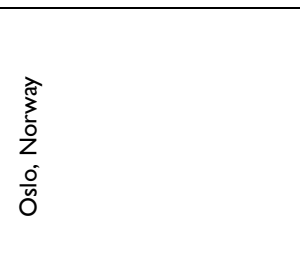 & 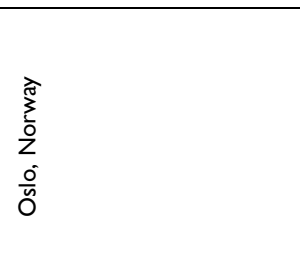 & 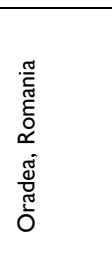 & 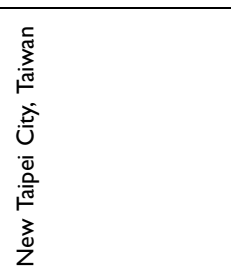 \\
\hline & 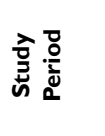 & $\begin{array}{l}\overline{\grave{a}} \\
\text { ì } \\
\text { ò }\end{array}$ & $\begin{array}{l}\overline{0} \\
\text { ì } \\
\text { ò }\end{array}$ & 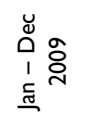 & 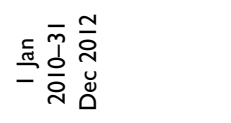 \\
\hline & 高 & 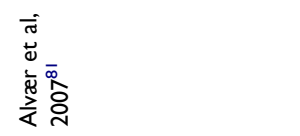 & 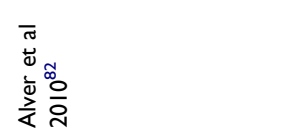 & 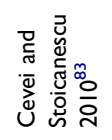 & 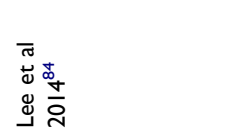 \\
\hline
\end{tabular}




\begin{tabular}{|c|c|}
\hline$\infty$ & r \\
\hline 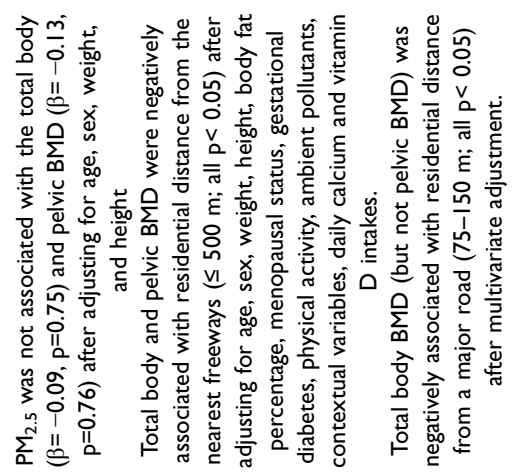 & 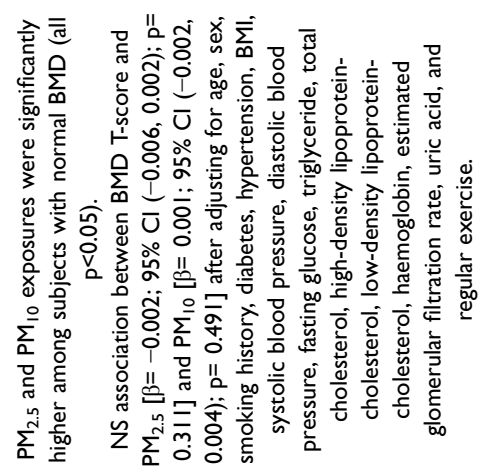 \\
\hline 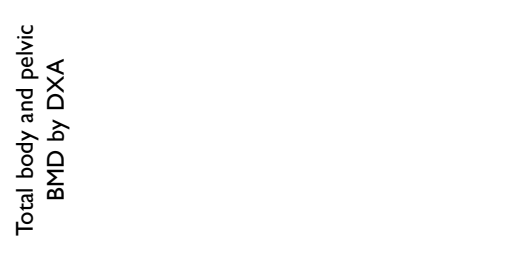 & 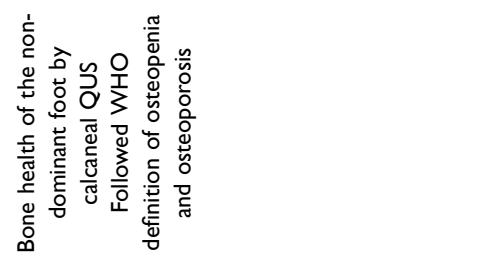 \\
\hline 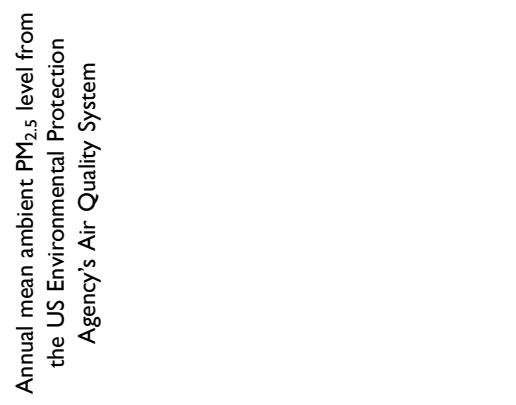 & 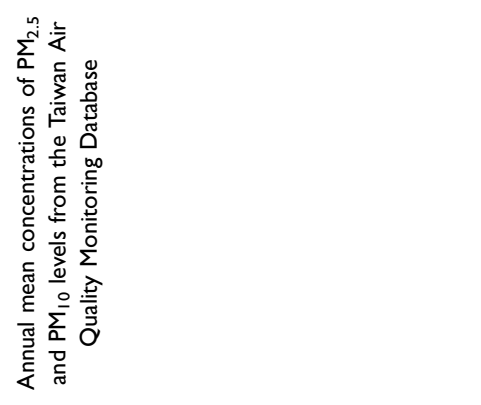 \\
\hline 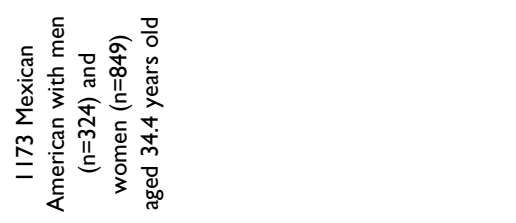 & 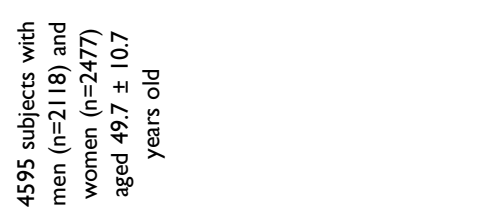 \\
\hline 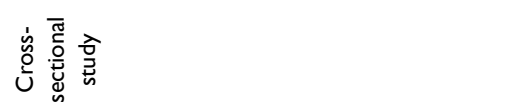 & 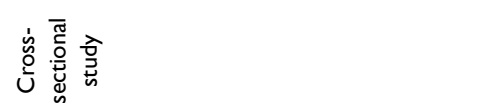 \\
\hline 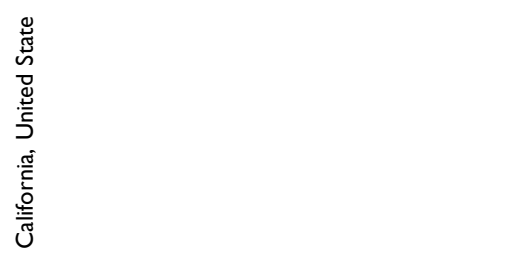 & 产 \\
\hline 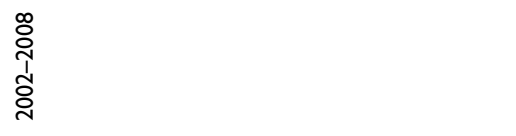 & 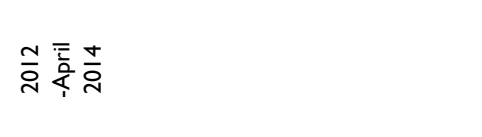 \\
\hline 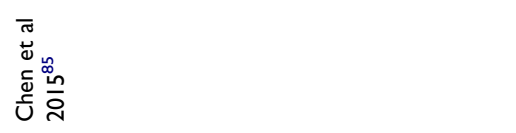 & 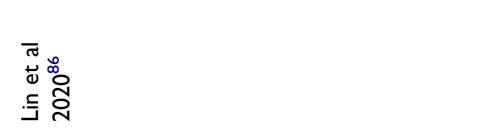 \\
\hline
\end{tabular}




\begin{tabular}{|c|c|c|c|}
\hline & $\overline{\underline{\underline{m}}}$ & n & $\infty$ \\
\hline & 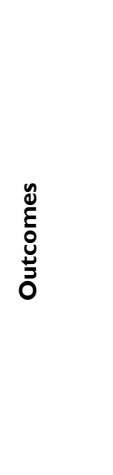 & 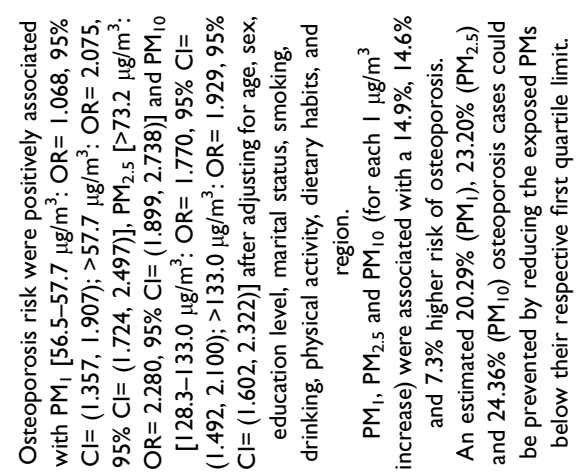 & 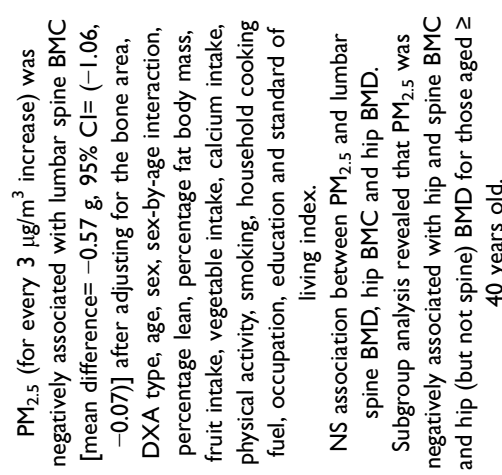 \\
\hline & 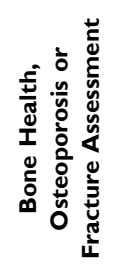 & 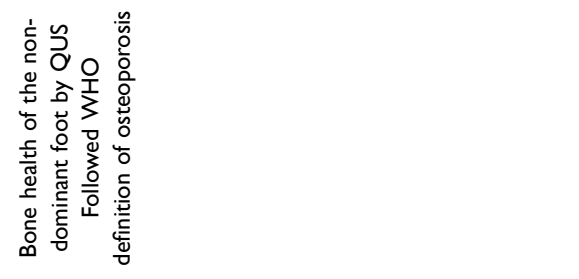 & 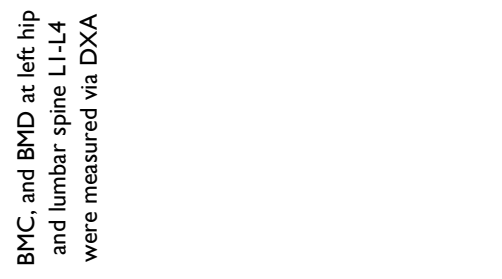 \\
\hline 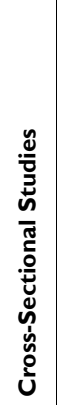 & 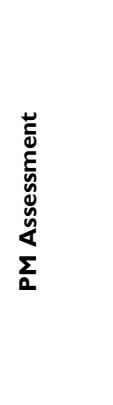 & 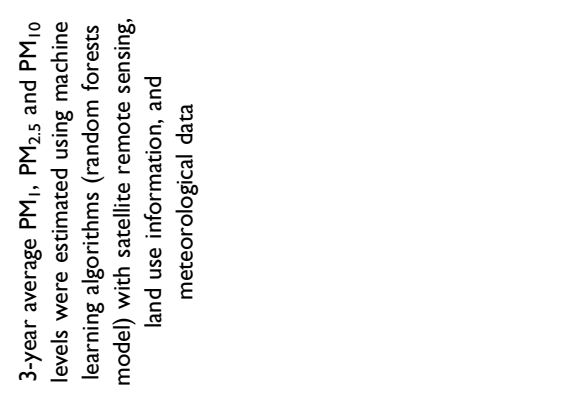 & 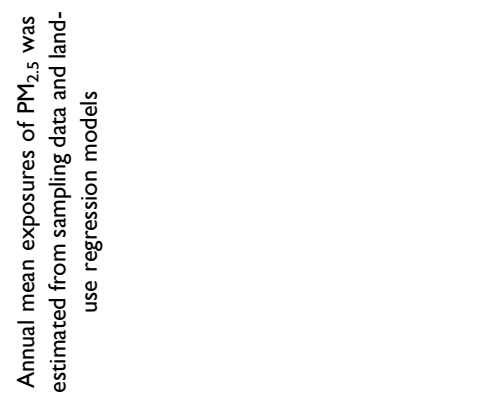 \\
\hline & 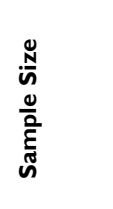 & 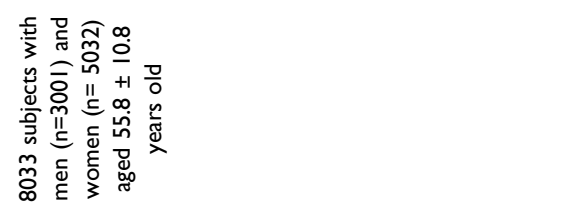 & 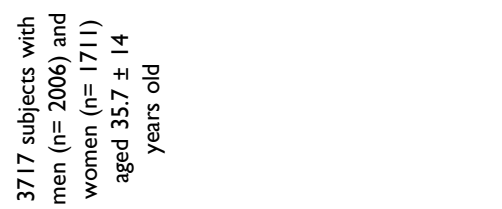 \\
\hline & 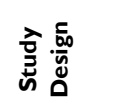 & 蔐 & 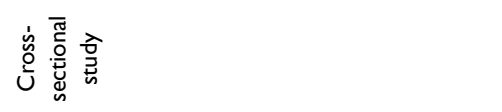 \\
\hline & 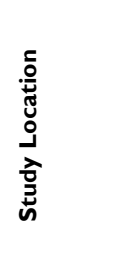 & 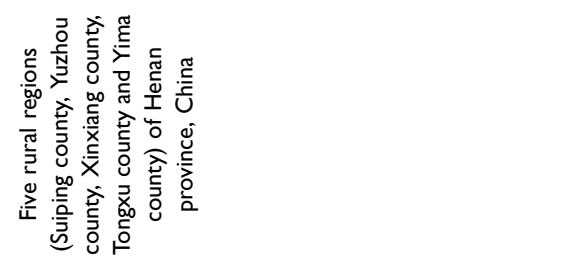 & 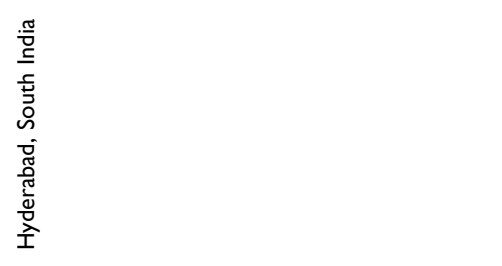 \\
\hline & 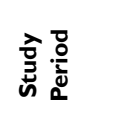 & 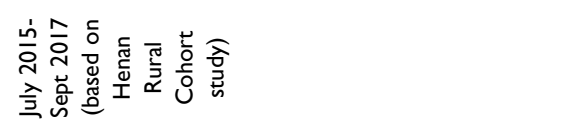 & $\begin{array}{l}1 \\
\text { Tें } \\
\text { òे } \\
\text { वे }\end{array}$ \\
\hline & 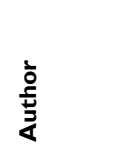 & 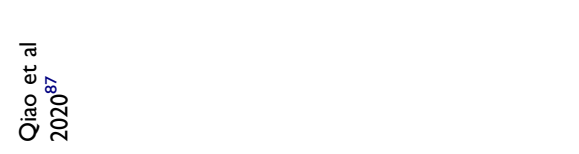 & 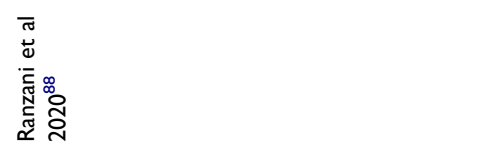 \\
\hline
\end{tabular}




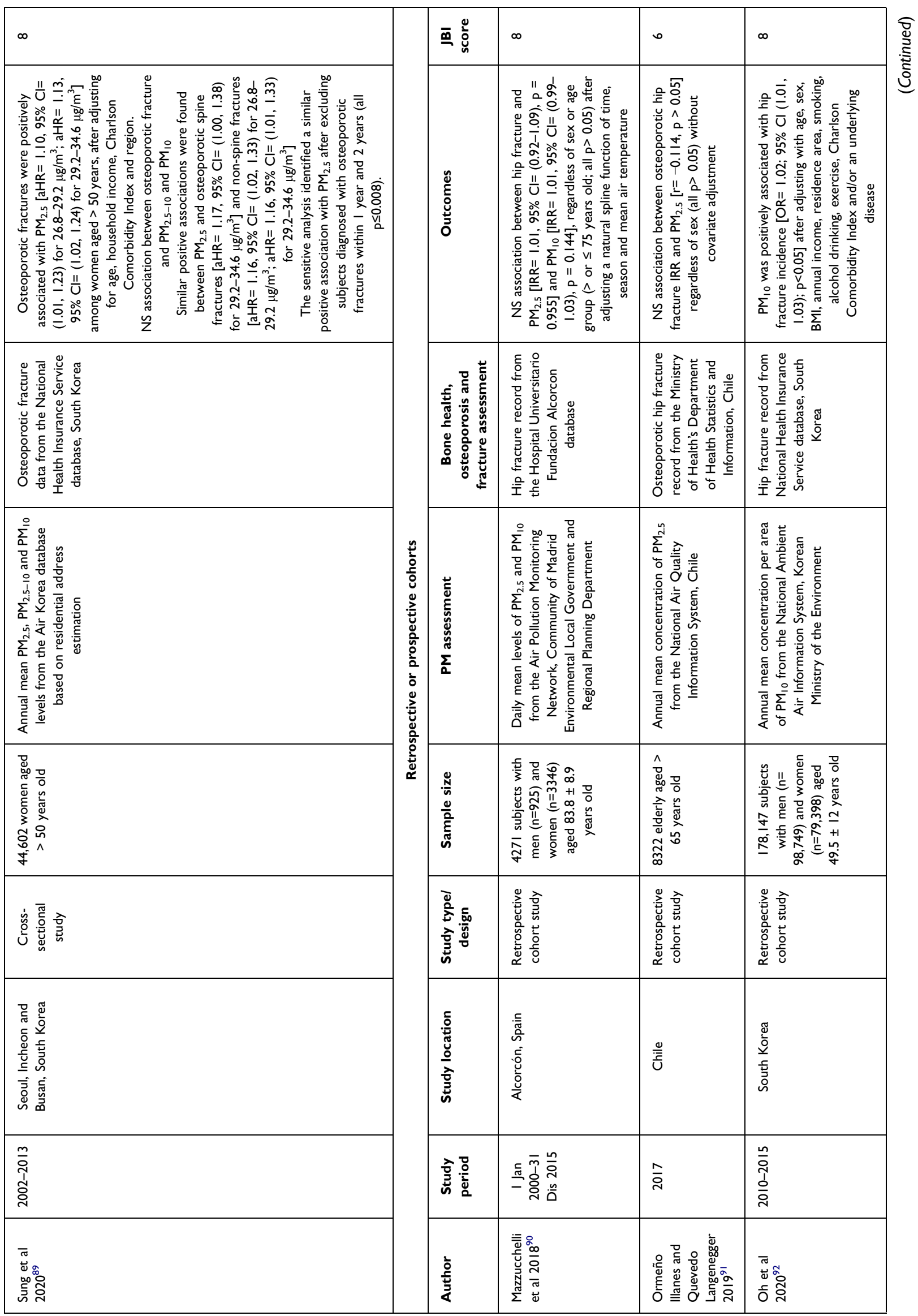




\begin{tabular}{|c|c|c|c|}
\hline & $\overline{\underline{\underline{m}}} \stackrel{0}{\grave{u}}$ & $\infty$ & $\infty$ \\
\hline & 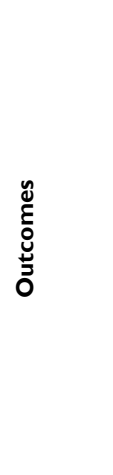 & 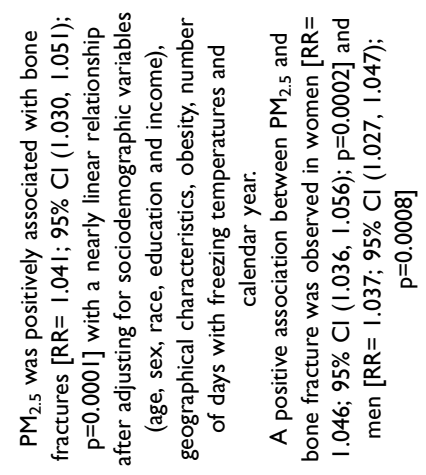 & 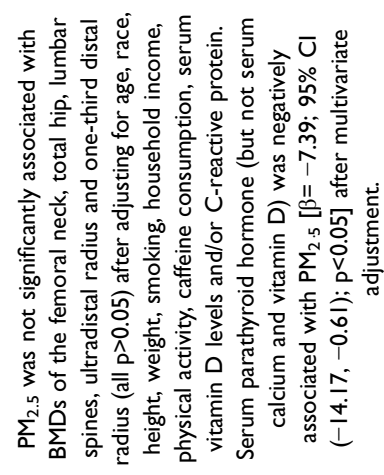 \\
\hline & 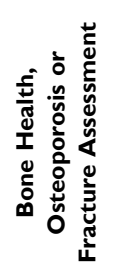 & 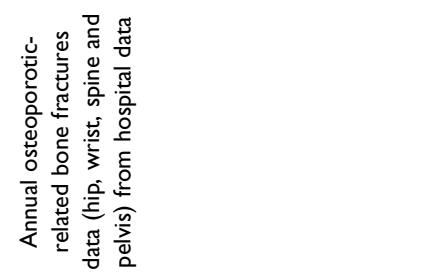 & 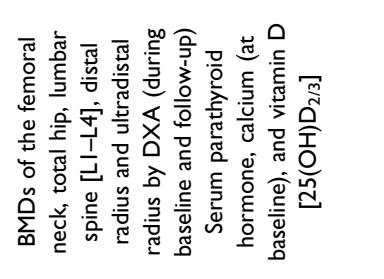 \\
\hline & 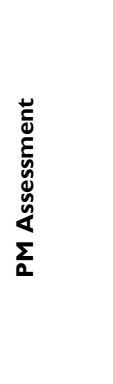 & 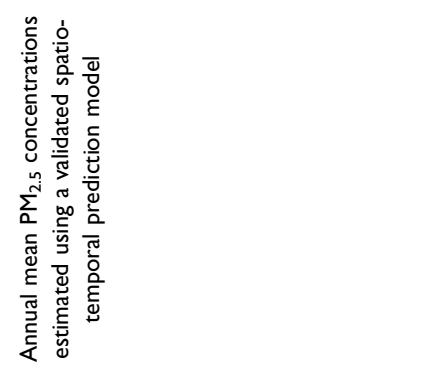 & 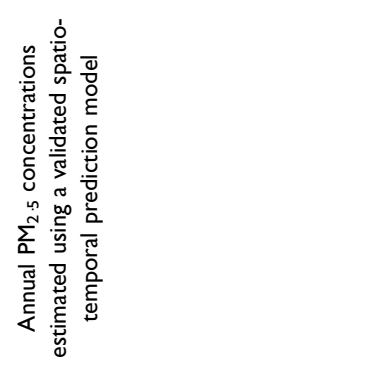 \\
\hline & 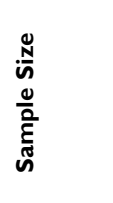 & 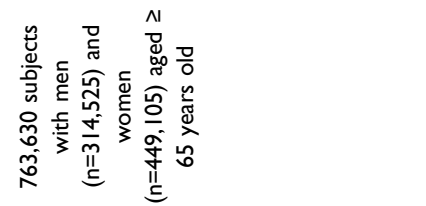 & 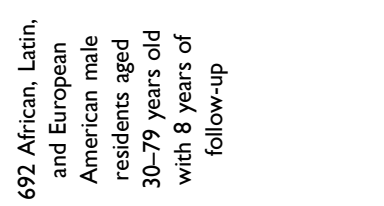 \\
\hline & 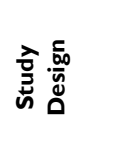 & 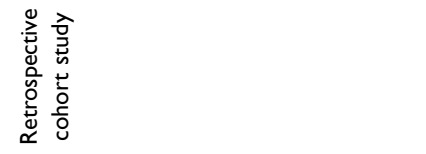 & 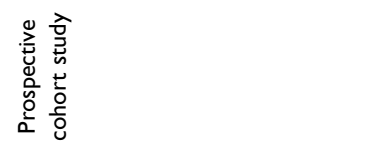 \\
\hline & 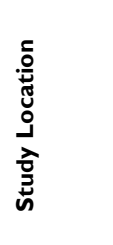 & 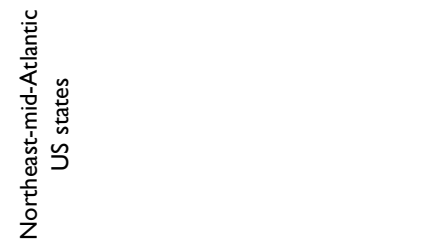 & 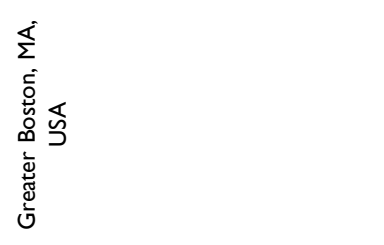 \\
\hline & 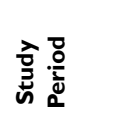 & 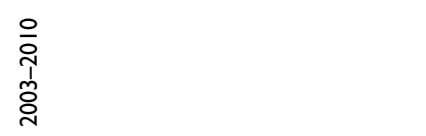 & 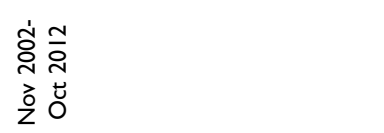 \\
\hline & & 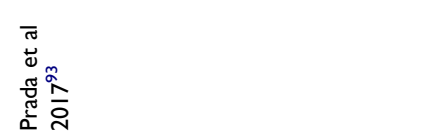 & \\
\hline
\end{tabular}




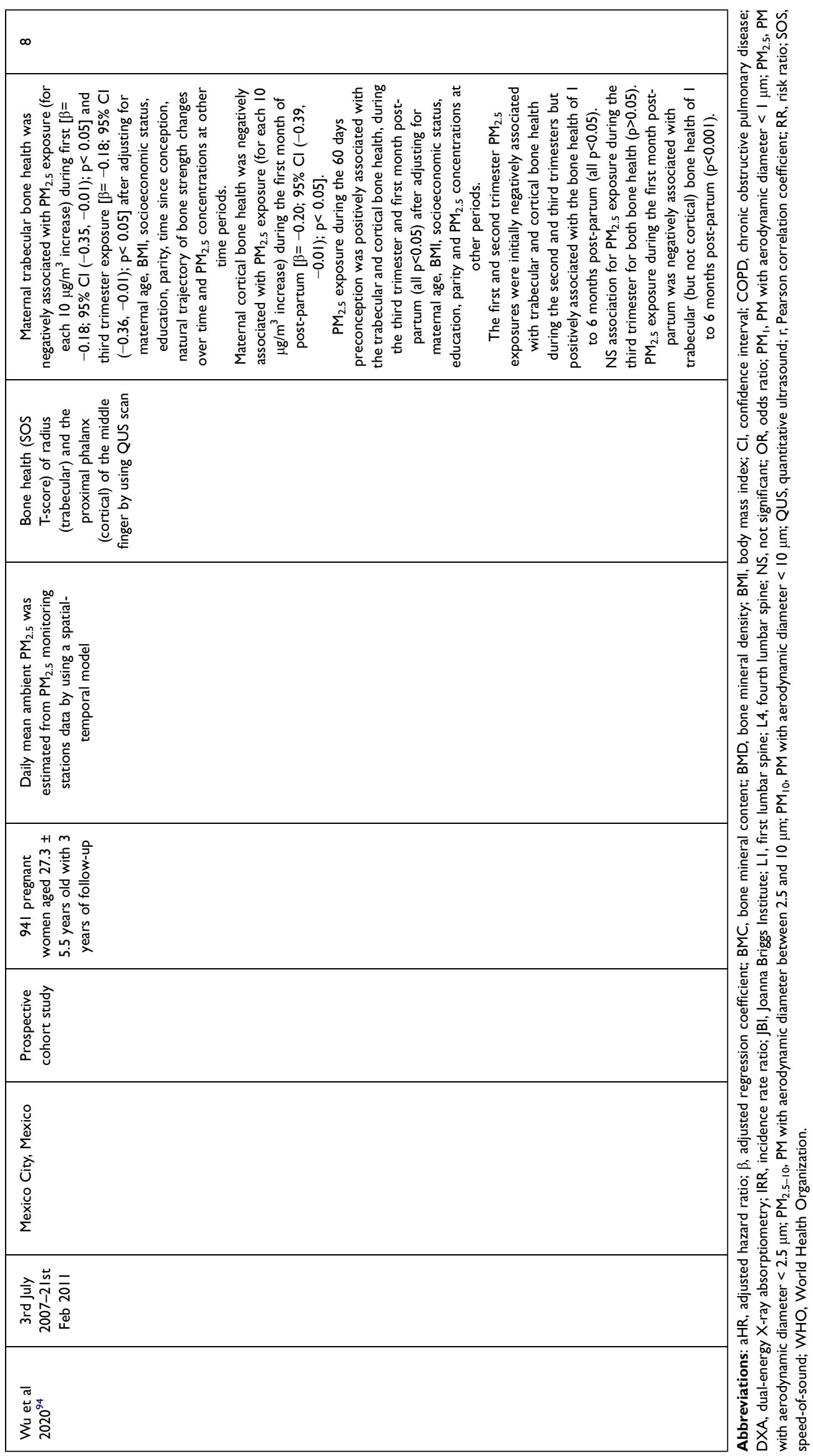




\section{Quality Assessment}

Two reviewers (K.-L.P. and S.O.E.) independently evaluated the article quality using the Joanna Briggs Institute (JBI) critical appraisal checklist. ${ }^{79,80}$ Two different checklists were used for cross-sectional and cohort studies covering "Sampling", "Exposure", "Confounding factors", "Outcomes" and "Statistical analysis" domains, with a maximum score of 8 (cross-sectional study) or 11 (cohort study). Every item was rated as Yes (score of 1), No or Unclear (score of 0). Non-applicable item is excluded from the overall scoring. Cross-sectional or retrospective cohort studies with an overall score $\geq 6$ or prospective cohort studies with $\geq 8$ were considered as high-quality articles. Any disagreement was resolved by discussion among three reviewers. The overall score was listed in the evidence table (Table 1) and detailed scoring was shown in Supplementary Table S3 and S4.

\section{Result}

\section{Search Results and Study Selection}

We identified 1500 articles, of which 401 were obtained from PubMed, 562 from Scopus, 441 from the Web of Science, 42 from Google Scholar, 25 from Cochrane Library and 18 additional articles from the reference list of included articles and reviews. A total of 1042 unique records were identified after excluding 458 duplicates. A total of 970 articles were excluded based on the inclusion and exclusion criteria where 19 articles were not written in English, 68 articles were not primary articles, 129 articles were non-human studies, 22 articles studied cigarette smoking and 732 articles were irrelevant to the topic. A total of 72 articles fulfilling the criteria were assessed for eligibility. After examining the full-text, we excluded 58 articles, of which 1 article was a preprint manuscript, 36 articles did not perform bone health assessment and 21 articles did not measure the PM level. Finally, 14 articles were included in this systematic review.

\section{Study Characteristics}

The included studies were published between 2007 and 2020, wherein 9 articles were cross-sectional studies, ${ }^{81-89} 4$ were retrospective studies ${ }^{90-93}$ and 2 were prospective studies. ${ }^{93,94}$ All the articles are considered high quality according to JBI critical appraisal checklist as shown in Table S3 and S4. However, some studies have validity, ${ }^{81,82,86,87,94}$ confounding factor ${ }^{83,91}$ and subjects follow-up issues. ${ }^{93,94}$ Four studies were conducted in North and South America (the United
States, ${ }^{85,93}$ Chile $^{91}$ and Mexico ${ }^{94}$ ); 4 studies were conducted in Europe (Norway, ${ }^{81,82}$ Romania $^{83}$ and Spain ${ }^{90}$ ), and the remaining 6 studies were conducted in Asia (Taiwan, ${ }^{84,86}$ Henan province of China, ${ }^{87}$ India $^{88}$ and South Korea ${ }^{89,92}$ ). The total number of participants was $1,024,864$, wherein 68,861 were from cross-sectional studies and 956,003 were from cohort studies. Two cohort studies had a sample size $>100,000$ participants, ${ }^{92,93}$ whereas 8 studies had a sample size of 1000-100,000 participants, ${ }^{82,85-91}$ and the remaining 5 studies enrolled $<1000$ patients. ${ }^{81,83,84,93,94}$ The participants were mainly elderly, ${ }^{81-84,89-91,93}$ followed by middleaged adults, ${ }^{86,87,89,92,93}$ young adults ${ }^{85,88,93}$ and pregnant women. ${ }^{94}$

One study investigated $\mathrm{PM}_{1},{ }^{87} 11$ studies ${ }^{81,82,85-91,93,94}$ investigated $\mathrm{PM}_{2.5},{ }^{55,56,59-65,67,68} 9$ studies investigated $\mathrm{PM}_{10} 81-84,86,87,89,90,92$ and 1 study investigated PM with aerodynamic diameter between 2.5 and $10 \mu \mathrm{m}\left(\mathrm{PM}_{2.5-10}\right){ }^{89}$ Most of the studies reported the annual mean concentration of PM, except studies by Mazzucchelli et $\mathrm{al}^{90}$ and Wu et $\mathrm{al}^{94}$ that used the daily mean PM levels (averaged across the study period). WHO air quality guidelines stated that the annual mean $\mathrm{PM}_{2.5}$ and $\mathrm{PM}_{10}$ levels should not exceed 10 and $20 \mu \mathrm{g} / \mathrm{m}^{3}$ respectively. ${ }^{95}$ The permissible limit for $\mathrm{PM}_{1}$ has not been established by WHO or other organisations. Most of the study locations had PM level exceeding the permissible limit with an annual mean $\mathrm{PM}_{2.5}$ levels $\leq 10 \mu \mathrm{g} /$ $\mathrm{m}^{3,}{ }^{81,82,91} 10-20 \mu \mathrm{g} / \mathrm{m}^{3},{ }^{85,86,91,93}$ or $>20 \mu \mathrm{g} / \mathrm{m}^{3},{ }^{87-89,91}$ and the annual mean $\mathrm{PM}_{10}$ levels $\leq 20 \mu \mathrm{g} / \mathrm{m}^{3},{ }^{81,82}$ or $>20 \mu \mathrm{g} /$ $\mathrm{m}^{3} \cdot 83,84,86,87,89,92$ Mazzucchelli et $\mathrm{al}^{90}$ reported a daily mean $\mathrm{PM}_{2.5}$ and $\mathrm{PM}_{10}$ of $9.52-12.34 \mu \mathrm{g} / \mathrm{m}^{3}$ and $23.47-$ $31.02 \mu \mathrm{g} / \mathrm{m}^{3}$ respectively, while $\mathrm{Wu}$ et $\mathrm{a}^{94}$ reported a daily mean $\mathrm{PM}_{2.5}$ of $22.3-23.5 \mu \mathrm{g} / \mathrm{m}^{3}$.

The bone health status was reported either as fracture incidence, ${ }^{82,89-93} \mathrm{BMC}$ and $\mathrm{BMD}$ assessed via DXA $^{81-85,88,93}$ or QUS method. ${ }^{86,87,94}$ BMDs of total body, ${ }^{81,83,85}$ pelvic, ${ }^{85}$ hip, ${ }^{84,88,93}$ femoral neck, ${ }^{83,84,93}$ lumbar spine ${ }^{83,84,88,93}$ distal forearm, ${ }^{82}$ distal radius ${ }^{93}$ and ultradistal radius ${ }^{93}$ were measured. Besides, Lin et $\mathrm{al}^{86}$ Qiao et $\mathrm{al}^{87}$ and $\mathrm{Wu}$ et $\mathrm{al}^{94}$ measured bone health via QUS method without DXA validation. Four studies $^{83,84,86,87}$ adopted the WHO definition of osteopenia and/or osteoporosis to classify the subjects.57,58,60,61 Besides, Alvær et al $^{81}$ defined subjects with Z-score $\leq-1$ as having low BMD, which does not comply with the existing recommendation. Adjusted regression coefficient $(\beta),{ }^{81,82,85,86,93,94}$ odd ratio (OR), ${ }^{81,82,84,87}$ mean differences, ${ }^{86,88}$ or Pearson correlation coefficient $(r)^{83}$ were used in these studies to 
demonstrate the association between PM and bone mass. For the association between PM and bone fracture, $\beta,{ }^{82}$ adjusted hazard ratio, ${ }^{89}$ incidence rate ratio (IRR), ${ }^{90} \mathrm{r}^{91} \mathrm{OR}^{92}$ and risk ratio ${ }^{93}$ were used.

\section{Relationship Between PM Exposure and Bone Health or Osteoporosis Risk}

The relationship between $\mathrm{PM}_{1}$ and bone health was scarce. Only a study by Qiao et $\mathrm{al}^{87}$ demonstrated that osteoporosis risk was positively associated with $\mathrm{PM}_{1}$ exposure after multivariate adjustment. Logistic regression analysis also showed that every $1 \mu \mathrm{g} / \mathrm{m}^{3}$ increase in $\mathrm{PM}_{1}$ was associated with a $14.9 \%$ increased risk of osteoporosis. ${ }^{87}$ Besides, an estimated $20.29 \%$ of $\mathrm{PM}_{1}$-related osteoporosis cases could be prevented if $\mathrm{PM}_{1}$ exposure was $<55.2 \mu \mathrm{g} / \mathrm{m}^{3}{ }^{87}$ Subgroup analysis revealed that the association between $\mathrm{PM}_{1}$ and risk of osteoporosis were significantly higher among non-alcoholic drinkers, but it was not affected by age, sex, smoking, vegetable or fruit consumption and physical activity. ${ }^{87}$ However, this study classified osteoporosis based on QUS assessment of non-dominant foot without DXA validation, which could introduce misclassification bias in the study.

The relationship of $\mathrm{PM}_{2.5}$ and/or $\mathrm{PM}_{10}$ with bone mass or osteoporosis risk was heterogeneous in other reports, whereby they revealed an insignificant ${ }^{82,84-86,93}$ or negative association. ${ }^{81,83,87,88,94}$ A cross-sectional study (Oslo Health study) on 1039 subjects aged 59-60 and 75-76 years old by Alver et $\mathrm{al}^{82}$ demonstrated that the distal forearm BMD was not significantly associated with $\mathrm{PM}_{2.5}$ and $\mathrm{PM}_{10}$ exposures regardless of age and sex after multivariate adjustment. Similarly, a cross-sectional study by Chen et al ${ }^{85}$ also reported that ambient $\mathrm{PM}_{2.5}$ exposure was not significantly associated with total body and pelvic BMDs among 1173 Mexican American women with an average age of 34.4 years after covariate adjustment. Lee et $\mathrm{al}^{84}$ reported that osteoporosis risk was not significantly associated with $\mathrm{PM}_{10}$ exposure among 70 COPD patients aged $75.2 \pm 5.5$ years after multivariate adjustment. Similarly, Prada et $\mathrm{al}^{93}$ also reported that $\mathrm{PM}_{2.5}$ exposure was not significantly associated with femoral neck and ultradistal radius BMDs in a population-based prospective cohort study with 692 men aged 30-79 years old after 8-year of follow-up. Another recent cross-sectional study by Lin et $\mathrm{al}^{86}$ on 4595 Taiwanese $\left(49.7 \pm 10.7\right.$ years old) also revealed that $\mathrm{PM}_{2.5}$ and $\mathrm{PM}_{10}$ exposures were not significantly associated with QUS readings of the non-dominant foot. In their study, the bone health of subjects remained normal even they were exposed to higher levels of $\mathrm{PM}_{2.5}{ }^{86}$

Other studies demonstrated that PM exposure is a significant risk factor for osteoporosis. The cross-sectional Oslo Health study (590 men aged 75-76 years) demonstrated that total body BMD was negatively associated with $\mathrm{PM}_{2.5}$ and $\mathrm{PM}_{10}$ after multivariate adjustment. ${ }^{81}$ Besides, the risk of low total body BMD (Z-score <-1) was positively associated with $\mathrm{PM}_{2.5}$ and $\mathrm{PM}_{10}$ exposures. ${ }^{81}$ Similarly, a cross-sectional study involving 105 Romanians by Cevei and Stoicanescu ${ }^{83}$ reported that the total body BMD (but not hip) was negatively associated with $\mathrm{PM}_{10}$ exposure without covariate adjustment. Additionally, a similar negative association of $\mathrm{PM}_{2.5}$ and $\mathrm{PM}_{10}$ exposures with bone health was reported in two recent cross-sectional studies by Qiao et $\mathrm{al}^{87}$ and Ranzani et al. ${ }^{88}$ The osteoporosis risk was positively associated with $\mathrm{PM}_{2.5}$ and $\mathrm{PM}_{10}$ exposures among 8033 Chinese $(55.8 \pm 10.8$ years old) from the rural area after multivariate adjustment. ${ }^{87}$ Subsequent logistic regression analysis also demonstrated that every $1 \mu \mathrm{g} / \mathrm{m}^{3}$ increase in $\mathrm{PM}_{2.5}$ and $\mathrm{PM}_{10}$ were associated with a respective $14.6 \%$ and $7.3 \%$ increase in osteoporosis risk. ${ }^{87}$ Besides, an estimated $23.20 \%$ and $24.36 \%$ of $\mathrm{PM}_{2.5}$ and $\mathrm{PM}_{10}$-related osteoporosis cases could be prevented if $\mathrm{PM}_{2.5}$ and $\mathrm{PM}_{10}$ exposure were less than 70.5 and $125.8 \mu \mathrm{g} / \mathrm{m}^{3}$ respectively. ${ }^{87}$ Subgroup analysis also demonstrated similar associations between osteoporosis risk and $\mathrm{PM}_{2.5}$ and $\mathrm{PM}_{10}$ among non-alcoholic drinkers or subjects with low physical activity. ${ }^{87}$ Ranzani et al ${ }^{88}$ reported that $\mathrm{PM}_{2.5}$ was associated with lumbar spine BMC but not with left hip BMC, left hip BMD and lumbar spine BMD among 3717 Indian (35.7 \pm 14 years old) after multivariate adjustment. Subgroup analysis revealed $\mathrm{PM}_{2.5}$ exposure was also negatively associated with left hip BMC and BMD, as well as lumbar spine BMC among subjects aged $\geq 40$ years old. ${ }^{88}$

Another recent prospective cohort study on 941 Mexican pregnant women with 3-year of follow-up by $\mathrm{Wu}$ et $\mathrm{al}^{94}$ also reported that maternal trabecular bone health was negatively associated with $\mathrm{PM}_{2.5}$ exposure during first- and third-trimester exposure. Besides, maternal cortical bone health was also negatively associated with $\mathrm{PM}_{2.5}$ exposure during the first trimester. ${ }^{94} \mathrm{~A}$ timespecific subgroup analysis revealed that these associations were biphasic across the time of exposure. $\mathrm{PM}_{2.5}$ exposure during 60-day preconception was positively associated with maternal bone health during mid-to-late gestation 
but turned into a negative association during 1 to 6 months post-partum period. ${ }^{94} \mathrm{PM}_{2.5}$ exposures during the firstand second-trimester were initially negatively associated with trabecular and cortical bone health during mid-to-late gestation but then positively associated with bone health during 1 to 6 months post-partum. ${ }^{94}$ Higher $\mathrm{PM}_{2.5}$ exposure during the third trimester and first month post-partum predicted a slower post-partum bone health recovery. ${ }^{94} \mathrm{Wu}$ et al considered the radius and proximal phalanx of the middle finger to represent trabecular and cortical bones respectively. We believed that it is a misnomer as QUS cannot differentiate between trabecular and cortical bone, particularly at the radius, which consists of both trabecular and cortical bones.

\section{Relationship of PM Exposure and Bone Fractures}

Similar to bone health, the relationship between PM exposure with bone fracture was also heterogeneous, wherein insignificant $^{82,89-91}$ or positive associations ${ }^{89,92,93}$ have been reported. A cross-sectional study from Alver et $\mathrm{al}^{82}$ reported that self-reported forearm fracture was not significantly associated with $\mathrm{PM}_{2.5}$ and $\mathrm{PM}_{10}$ exposure among 5976 elderly regardless of age and sex. Besides, a retrospective cohort study by Mazzucchelli et al ${ }^{90}$ reported $\mathrm{PM}_{2.5}$ and $\mathrm{PM}_{10}$ were not significantly associated with hip fracture among 4271 elderly aged $83.8 \pm 8.9$ years after univariate or multivariate adjustment. Parallelly, another retrospective study by Ormeño Illanesalso and Quevedo Langenegger $^{91}$ on 8322 Chilean people aged $\geq 65$ years also reported that the association between $\mathrm{PM}_{2.5}$ and osteoporotic hip fracture was not significant regardless of sex. Subjects from Magallanes (the lowest $\mathrm{PM}_{2.5}$ region in Chile) and Aysén region (the highest $\mathrm{PM}_{2.5}$ region) showed similar IRR for bone fractures. ${ }^{91}$ Nevertheless, the results of this study were not adjusted for confounding factors. $^{91}$

On the other hand, a recent cross-sectional study from Sung et $\mathrm{al}^{89}$ on 44,602 South Korean women aged $>50$ years old revealed that $\mathrm{PM}_{2.5}$ exposure but not $\mathrm{PM}_{2.5-10}$ and $\mathrm{PM}_{10}$ was positively associated with osteoporotic fractures, including both spine and non-spine fractures. A similar positive association was also reported after excluding the subjects with an osteoporotic fracture in the recent 1 to 2 years. ${ }^{89}$ Additionally, retrospective cohort studies by Prada et al $^{93}$ demonstrated a positive association between osteoporotic-related bone fracture and $\mathrm{PM}_{2.5}$ exposure among 763,630 residents aged $\geq 65$ years old from Northeast-mid-Atlantic US states, which also present in men and women subgroups. ${ }^{93}$ A nearly linear relationship between $\mathrm{PM}_{2.5}$ exposure and bone fracture rate was reported across the range between 3 and $22 \mu \mathrm{g} / \mathrm{m}^{3} \quad \mathrm{PM}_{2.5}$ level. ${ }^{93}$ Besides, a recent retrospective cohort study on 178,147 South Korean aged $49.5 \pm 12$ years old by Oh et $\mathrm{al}^{92}$ also demonstrated that $\mathrm{PM}_{10}$ was positively associated with hip fracture incidence after multivariate adjustment. Nevertheless, this study was limited by the relatively low hip fracture incidence $(n=919)$ compared to healthy control $(n=177,228){ }^{92}$

\section{Discussion}

The relationships between PM exposure, including $\mathrm{PM}_{1}$, $\mathrm{PM}_{2.5}, \mathrm{PM}_{2.5-10}$ and $\mathrm{PM}_{10}$, with bone health and fracture incidence are not conclusive based on current evidence. $\mathrm{PM}_{2.5}$ and/or $\mathrm{PM}_{10}$ exposures were demonstrated to be associated with bone fracture positively ${ }^{89,92,93}$ or not significantly. ${ }^{82,89-91}$ Similarly, the association between $\mathrm{PM}_{2.5}$ and/or $\mathrm{PM}_{10}$ with bone mass was negative ${ }^{81,83,87,88,94}$ or not significant. $^{82,84-86,93}$ Interestingly, $\mathrm{Wu}$ et al demonstrated a time-specific biphasic association between $\mathrm{PM}_{2.5}$ exposure and bone health measured by QUS among pregnant women. On the other hand, relevant findings on $\mathrm{PM}_{1}$ are scarce as only one study demonstrates a positive association with osteoporosis. ${ }^{87}$ The relationship between $\mathrm{PM}_{1}$ and bone fracture is yet to be determined. Besides, only one study reported a non-significant association between $\mathrm{PM}_{2.5-10}$ and osteoporotic fractures, ${ }^{89}$ and its relationship with bone mass is yet to be determined.

The inconsistent findings in the relationship between PM and bone mass/fracture may be partly due to the heterogeneous sample size. Five included studies with sample sizes of less than 1000 patients may not accurately represent the studied population and introduce bias in interpretation. ${ }^{81,83,84,93,94}$ Besides, an appropriate adjustment for confounding factors is essential to avoid confounding effects and false interpretation of causality. For instance, Alver et $\mathrm{al}^{82}$ reported that distal forearm BMD was negatively associated with $\mathrm{PM}_{2.5}$ and $\mathrm{PM}_{10}$ levels among men aged 75-76 years old. However, these associations were not significant after adjustment for education, smoking, years of smoking, physical activity and years after menopause. Similarly, Ranzani et $\mathrm{al}^{88}$ also reported that the negative association between $\mathrm{PM}_{2.5}$ exposure and lumbar spine BMD became insignificant after 
adjusting for additional covariates. Additionally, several included studies did not perform covariate adjustment, ${ }^{83,91}$ casting some doubts on the validity of the results. Furthermore, critical covariates such as sunlight exposure, vitamin D level, dietary pattern and inflammatory status were not considered in most of the included studies, contributing to the inconsistency of findings.

Additionally, the detection methods of PM may partly contribute to the inconsistent findings in the relationship between PM and bone mass/fracture. PM metric like particle mass is commonly measured using gravimetric and optical methods. ${ }^{96}$ However, these detection technologies vary in terms of practicability (cost, size, noisiness and mobility), precision, accuracy and sensitivity/detection limits. ${ }^{96}$ Studies included in the current review assessed the PM data, but the underlying detection technologies were not disclosed. Additionally, PM statistical modelling is commonly used to estimate and predict indoor air quality and individual exposure to PM because direct individual PM exposure measurement is technically impractical or difficult to be performed. ${ }^{97}$ There are several factors needed to be considered in developing and calibrating the PM levels, including geographical location, meteorological/climate conditions and aerosol optical depth. ${ }^{97,98}$ Most studies employed a spatiotemporal prediction model by adjusting the subjects' geographical or residential location. However, some studies did not describe how individual PM exposure estimation was performed or PM modelling was developed. ${ }^{83,84,89,91,92}$ Some studies employed the previously reported prediction model ${ }^{81,82}$ or self-developed spatiotemporal prediction model without disclosing the cross-validation values. ${ }^{85,86,90}$ In several studies, the PM model was adjusted/calibrated for climate, weather and/or traffic conditions. ${ }^{85,87,93,94}$ However, some studies like Lee et al and Mazzucchelli et al measured the climate and weather conditions but did not include them in PM model calibration. ${ }^{84,90}$ The remaining studies did not disclose the PM modeling calibration. It is noteworthy that variations in PM modelling may contribute to inaccurate individual PM exposure estimation, leading to inconsistency in the findings between PM exposure and bone health.

Osteoporosis is diagnosed based on the BMD T-score of any major common bone fracture sites, such as at the spine, hip or mid-radius. ${ }^{44}$ However, T-score discordance at different bone sites is not an unusual observation, ${ }^{100-102}$ probably due to the non-homogeneous process of bone loss. ${ }^{103,104}$ Increasing the number of bone sites scanned will increase the chance of discordance and detecting osteoporosis. ${ }^{100}$ Thus, the number of bone sites examined could influence the relationship between PM exposure and osteoporosis risk. As evidence, Cevei and Stoicanescu ${ }^{83}$ and Ranzani et al ${ }^{88}$ demonstrated inconsistent associations between PM and bone mass at different sites. Moreover, several studies ${ }^{81,83,85}$ employed the total body BMD as the skeletal outcome of interest, which is less sensitive than regional BMDs. ${ }^{105}$ Although total body BMD correlates with regional BMDs, ${ }^{103}$ this value is not used to diagnose osteoporosis per WHO recommendation. Besides, some studies used QUS to define the bone health of the subjects. ${ }^{86,87,94}$ DXA and QUS adopt different technology in identifying bone health, so their results are not interchangeable. $^{48}$ The WHO classification system to diagnose osteoporosis based on BMD T-score cannot be used for QUS. ${ }^{106}$ Although QUS indices correlate with bone mass and several bone microarchitectural indices, ${ }^{48}$ they cannot be used directly to infer bone strength as in the studies of Wu et al. ${ }^{94} \mathrm{~A}$ biomechanical assessment, like the three-point bending flexural test,${ }^{107}$ can indicate bone strength directly. ${ }^{108}$ However, the destructive nature of this test prohibits its use among live subjects. Reference point indentation or micro-indentation test is an alternative method to estimate bone strength in vivo directly. ${ }^{109}$ Additionally, PM species are generally present together ${ }^{82,87}$ and coexist with other air pollutants like nitrogen monoxide, $\mathrm{NO}_{2}$ and $\mathrm{SO}_{2} \cdot{ }^{87,90}$ These air pollutants were reported positively correlated with osteoporosis risk. ${ }^{86,99}$ Besides, there are synergistic effects between CO-nitrogen oxide and $\mathrm{SO}_{2}-\mathrm{NO}_{2}$, which could further reduce BMD. ${ }^{86}$ Therefore, it is impossible to attribute the skeletal effects to a single PM species or single air pollutants. Additionally, residential proximity to the nearest freeway $(\leq 500 \mathrm{~m})$ but not $\mathrm{PM}_{2.5}, \mathrm{NO}_{2}$ and $\mathrm{O}_{3}$ exposure was negatively associated with total body and pelvic BMD after multivariate adjustment, including the pollutants levels. ${ }^{85}$ This observation suggests that other air pollutants like PAHs or black carbon from vehicle exhaust emissions might also contribute to BMD reduction. $^{85,88}$

Previous studies observed a higher bone mass and fewer bone fractures among subjects from rural areas than urban areas. ${ }^{110-121}$ Several factors such as occupation, lifestyle, physical activity, dietary pattern and traffic accident are attributed to this observation. It would be interesting to ask whether air quality could contribute to the difference in bone health between rural and urban populations. However, studies included in this review showed that it might be erroneous to presume rural areas are less polluted. For instance, Qiao et $\mathrm{al}^{87}$ 
demonstrated 6 to 7 times high annual mean $\mathrm{PM}_{2.5}$ and $\mathrm{PM}_{10}$ levels in the rural area than the WHO air quality standard. High PM levels in the rural area could be contributed by increasing numbers of factory and biomass usage or burning fuel activities. ${ }^{53,59,87,122}$ Besides, biomass cooking in the rural area had been demonstrated to produce significantly higher $\mathrm{PM}_{2.5}$ and/or $\mathrm{PM}_{10}$ levels compared with liquid petroleum gas. ${ }^{53,59}$

This systematic review, like others, has its limitations. This review did not include unpublished, grey literature and proceeding articles without complete data. Besides, we limited those studies in the recent 30 years as PMrelated research began receiving attention from 1990 onwards. $^{123}$ However, it is still possible that we might miss out on some important studies. We tried to minimise this limitation by referring to the reference lists of included articles. Moreover, we did not perform a metaanalysis due to the heterogeneity of the study design, outcomes and analysis. The included studies consisted of cross-sectional, retrospective and prospective cohort studies adopting various statistical strategies, the definition of bone health and PM types, hindering meta-analysis from being conducted.

\section{Conclusion}

The current literature suggests an inconclusive association between PM exposures and osteoporosis risk and/or fracture, potentially due to the heterogeneity in subject characteristics, study design, sample size, outcome measurement and covariate adjustment during analysis among various studies. Further validation in human studies is required to validate the positive association between $\mathrm{PM}_{2.5}$ and/or $\mathrm{PM}_{10}$ and osteoporosis risk or fracture. Furthermore, most of the studies emphasised on $\mathrm{PM}_{2.5}$ and $\mathrm{PM}_{10}$ with a limited number of studies on $\mathrm{PM}_{1}$. It is crucial to investigate the potential relationship between $\mathrm{PM}_{1}$ and other ultrafine particles with bone health/fracture.

\section{Acknowledgments}

The authors thank the Universiti Kebangsaan Malaysia for the Research University Grant under grant number GUP2020-021. K.-L.P. and S.O.E are post-doctoral researchers funded by Universiti Kebangsaan Malaysia through RGA1 and FPR-1 grants.

\section{Disclosure}

The authors report no conflicts of interest in this work.

\section{References}

1. World Health Organization. Air pollution; 2021. Available from: https://www.who.int/health-topics/air-pollution\#tab=tab_1. Accessed March 23, 2021.

2. Chau TT, Wang KY. An association between air pollution and daily most frequently visits of eighteen outpatient diseases in an industrial city. Sci Rep. 2020;10. doi:10.1038/s41598-020-58721-0

3. Liu C, Ying Z, Harkema J, et al. Epidemiological and experimental links between air pollution and type 2 diabetes. Toxicol Pathol. 2013;41:361-373. doi:10.1177/0192623312464531

4. Block ML, Calderón-Garcidueñas L. Air pollution: mechanisms of neuroinflammation and cns disease. Trends Neurosci. 2009;32 (9):506-516. doi:10.1016/j.tins.2009.05.009

5. Brook Robert D, Rajagopalan S, Pope CA, et al. Particulate matter air pollution and cardiovascular disease. Circulation. 2010;121(21):2331-2378. doi:10.1161/CIR.0b013e3181dbece1

6. Jiang X-Q, Mei X-D, Feng D. Air pollution and chronic airway diseases: what should people know and do? J Thorac Dis. 2016;8 (1):E31-E40. doi:10.3978/j.issn.2072-1439.2015.11.50

7. Michalska M, Zorena K, Wąż $\mathrm{P}$, et al. Gaseous pollutants and particulate matter $(\mathrm{pm})$ in ambient air and the number of new cases of type 1 diabetes in children and adolescents in the pomeranian voivodeship, poland. Biomed Res Int. 2020;2020:1648264. doi:10.1155/2020/1648264

8. Ou JY, Hanson HA, Ramsay JM, et al. Fine particulate matter and respiratory healthcare encounters among survivors of childhood cancers. Int $J$ Environ Res Public Health. 2019;16(6):1081. doi:10.3390/ijerph16061081

9. Garcia-Perez J, Gomez-Barroso D, Tamayo-Uria I, et al. Methodological approaches to the study of cancer risk in the vicinity of pollution sources: the experience of a populationbased case-control study of childhood cancer. Int $J$ Health Geogr. 2019;18. doi:10.1186/s12942-019-0176-x

10. World Health Organization. Air quality and health; Types of pollutants; 2021. Available from: https://www.who.int/teams/ environment-climate-change-and-health/air-quality-and-health/ health-impacts/types-of-pollutants. Accessed March 23, 2021.

11. Najjar YSH. Gaseous pollutants formation and their harmful effects on health and environment. Innov Energy Policies. 2011;1:1-9. doi:10.4303/iep/E101203

12. Chow JC, Watson JG. Guideline on Speciated Particulate Monitoring. New York city, USA: US Environmental Protection Agency; 1998

13. Davidson CI, Phalen RF, Solomon PA. Airborne particulate matter and human health: a review. Aerosol Sci Technol. 2005;39 (8):737-749. doi:10.1080/02786820500191348

14. Harrison RM, Yin J. Particulate matter in the atmosphere: which particle properties are important for its effects on health? Sci Tot Environ. 2000;249(1):85-101. doi:10.1016/S0048-9697(99) 00513-6

15. Li D, Li Y, Li G, et al. Fluorescent reconstitution on deposition of pm2.5 in lung and extrapulmonary organs. Proc Natl Acad Sci. 2019;116(7):2488. doi:10.1073/pnas.1818134116

16. Cao L, Zeng J, Liu K, et al. Characterisation and cytotoxicity of $\mathrm{pm}<0.2$, pm0.2-2.5 and pm2.5-10 around mswi in shanghai, china. Int J Environ Res Public Health. 2015;12(5):5076-5089. doi:10.3390/ijerph120505076

17. Haghani A, Johnson R, Safi N, et al. Toxicity of urban air pollution particulate matter in developing and adult mouse brain: comparison of total and filter-eluted nanoparticles. Environ Int. 2020;136:105510. doi:10.1016/j.envint.2020.105510

18. Brzezina J, Köbölová K, Adamec V. Nanoparticle number concentration in the air in relation to the time of the year and time of the day. Atmosphere. 2020;11(5):523. doi:10.3390/atmos11050523 
19. Corbin JC. Pm0.1 particles from aircraft may increase risk of vascular disease. $B M J$. 2013;347:f6783. doi:10.1136/bmj.f6783

20. Cao G, Zhang X, Gong S, et al. Emission inventories of primary particles and pollutant gases for china. Chin Sci Bull. 2011;56 (8):781-788. doi:10.1007/s11434-011-4373-7

21. Dominici F, Greenstone M, Sunstein CR. Particulate matter matters. Science. 2014;344(6181):257. doi:10.1126/science. 1247348

22. Pope CA 3rd, Dockery DW. Acute health effects of pm10 pollution on symptomatic and asymptomatic children. Am Rev Respir Dis. 1992;145(5):1123-1128. doi:10.1164/ajrccm/145.5.1123

23. Dong L, Sun W, Li F, et al. The harmful effects of acute pm 2.5 exposure to the heart and a novel preventive and therapeutic function of ceos. Sci Rep. 2019;9(1):3495. doi:10.1038/s41598019-40204-6

24. Zhang L, Yang Y, Li Y, et al. Short-term and long-term effects of pm2.5 on acute nasopharyngitis in 10 communities of Guangdong, China. Sci Tot Environ. 2019;688:136-142. doi:10.1016/j.scitotenv.2019.05.470

25. Hvidtfeldt UA, Sørensen M, Geels C, et al. Long-term residential exposure to pm2.5, pm10, black carbon, no2, and ozone and mortality in a Danish cohort. Environ Int. 2019;123:265-272. doi:10.1016/j.envint.2018.12.010

26. Kloog I, Ridgway B, Koutrakis P, et al. Long- and short-term exposure to pm2.5 and mortality: using novel exposure models. Epidemiology (Cambridge, Mass). 2013;24(4):555-561. doi:10.1097/EDE.0b013e318294beaa

27. Pope CA, Burnett RT, Thurston GD, et al. Cardiovascular mortality and long-term exposure to particulate air pollution: epidemiological evidence of general pathophysiological pathways of disease. Circulation. 2004;109:71-77. doi:10.1161/01. CIR.0000108927.80044.7F

28. Consonni D, Carugno M, De Matteis S, et al. Outdoor particulate matter (pm10) exposure and lung cancer risk in the eagle study. PLoS One. 2018;13(9):e0203539. doi:10.1371/journal. pone.0203539

29. Madureira J, Slezakova K, Silva AI, et al. Assessment of indoor air exposure at residential homes: inhalation dose and lung deposition of pm10, pm2.5 and ultrafine particles among newborn children and their mothers. Sci Tot Environ. 2020;717:137293. doi:10.1016/j.scitotenv.2020.137293

30. Chen C-H, Wu C-D, Chiang H-C, et al. The effects of fine and coarse particulate matter on lung function among the elderly. Sci Rep. 2019;9(1):14790. doi:10.1038/s41598-019-51307-5

31. Manoj Kumar N, Sm BS. SN. Quantification of size segregated particulate matter deposition in human airways. $J$ Adv Res Altern Energy Environ Ecol. 2018;5:15-22. doi:10.24321/ 2455.3093.201803

32. Guo Z, Hong Z, Dong W, et al. Pm2. 5-induced oxidative stress and mitochondrial damage in the nasal mucosa of rats. Int $J$ Environ Res Public Health. 2017;14(2):134. doi:10.3390/ ijerph14020134

33. He M, Ichinose T, Yoshida $Y$, et al. Urban pm2. 5 exacerbates allergic inflammation in the murine lung via a tlr2/tlr4/myd 88 signaling pathway. Sci Rep. 2017;7(1):1-9. doi:10.1038/s41598016-0028-x

34. $\mathrm{Li} \mathrm{T}, \mathrm{Hu} \mathrm{R}$, Chen $\mathrm{Z}$, et al. Fine particulate matter (pm2.5): the culprit for chronic lung diseases in china. Chronic Dis Transl Med. 2018;4(3):176-186. doi:10.1016/j.cdtm.2018.07.002

35. O'Callaghan-Gordo C, Fthenou E, Pedersen M, et al. Outdoor air pollution exposures and micronuclei frequencies in lymphocytes from pregnant women and newborns in Crete, Greece (rhea cohort). Environ Res. 2015;143:170-176. doi:10.1016/j. envres.2015.10.011

36. Dumax-Vorzet AF, Tate M, Walmsley R, et al. Cytotoxicity and genotoxicity of urban particulate matter in mammalian cells. Mutagenesis. 2015;30(5):621-633. doi:10.1093/mutage/gev025
37. Wang T, Xia Z, Wu M, et al. Pollution characteristics, sources and lung cancer risk of atmospheric polycyclic aromatic hydrocarbons in a new urban district of Nanjing, China. J Environ Sci (China). 2017;55:118-128. doi:10.1016/j.jes.2016.06.025

38. Ginaldi L, Di Benedetto MC, De Martinis M. Osteoporosis, inflammation and ageing. Immun Ageing. 2005;2:14. doi:10.1186/1742-4933-2-14

39. Chin K, Pang K, Soelaiman IN. Tocotrienol and its role in chronic disease. In: Gupta SC, Prasad S, Aggarwal BB, editors. AntiInflammatory Nutraceuticals and Chronic Diseases. Vol. 928. Switzerland: Springer International Publishing; 2016:97-130.

40. Wong SK, Chin K-Y, Suhaimi FH, et al. The relationship between metabolic syndrome and osteoporosis: a review. Nutrients. 2016;8 (6). doi:10.3390/nu8060347

41. Looker AC, Sarafrazi Isfahani N, Fan B, et al. Trends in osteoporosis and low bone mass in older us adults, 2005-2006 through 2013-2014. Osteoporos Int. 2017;28(6):1979-1988. doi:10.1007/ s00198-017-3996-1

42. Alswat KA. Gender disparities in osteoporosis. J Clin Med Res. 2017;9(5):382-387. doi:10.14740/jocmr2970w

43. Frost SA, Nguyen ND, Center JR, et al. Excess mortality attributable to hip-fracture: a relative survival analysis. Bone. 2013;56 (1):23-29. doi:10.1016/j.bone.2013.05.006

44. World Health Organization. Assessment of Fracture Risk and Its Application to Screening for Postmenopausal Osteoporosis: Report of a Who Study Group. World Health Organization; 1994:9241208430.

45. World Health Organization. Who Scientific Group on the Assessment of Osteoporosis at Primary Health Care Level. Brussels, Belgium; May 5-7, 2004.

46. International Osteoporosis Foundation. Diagnosis; 2021. Available from: https://www.osteoporosis.foundation/patients/ diagnosis. Accessed March 20, 2021.

47. Subramaniam S, Chan CY, Soelaiman IN, et al. The performance of a calcaneal quantitative ultrasound device, $\mathrm{cm}-200$, in stratifying osteoporosis risk among Malaysian population aged 40 years and above. Diagnostics (Basel). 2020;10(4). doi:10.3390/ diagnostics 10040178

48. Chin KY, Ima-Nirwana S. Calcaneal quantitative ultrasound as a determinant of bone health status: what properties of bone does it reflect? Int J Med Sci. 2013;10(12):1778-1783. doi:10.7150/ ijms. 6765

49. Compston J, Cooper A, Cooper C, et al. UK clinical guideline for the prevention and treatment of osteoporosis. Arch Osteoporos. 2017;12(1):43. doi:10.1007/s11657-017-0324-5

50. Nguyen TV. Air pollution: a largely neglected risk factor for osteoporosis. Lancet Planet Health. 2018;1:e311-e312. doi:10.1016/S2542-5196(17)30143-2

51. Nguyen VH. Environmental air pollution and the risk of osteoporosis and bone fractures. J Prev Med Public Health. 2018;51:215-216. doi:10.3961/jpmph.18.114

52. Prada D, López G, Solleiro-Villavicencio H, et al. Molecular and cellular mechanisms linking air pollution and bone damage. Environ Res. 2020;185:109465. doi:10.1016/j.envres.202 0.109465

53. Saha H, Mukherjee B, Bindhani B, et al. Changes in rankl and osteoprotegerin expression after chronic exposure to indoor air pollution as a result of cooking with biomass fuel. J Appl Toxicol. 2015;36:969-976. doi:10.1002/jat.3275

54. Peters A, Frohlich M, Doring A, et al. Particulate air pollution is associated with an acute phase response in men - results from the Monica-Augsburg study. Eur Heart J. 2001;22:1198-1204. doi:10.1053/euhj.2000.2483

55. Vossoughi M, Schikowski T, Vierkotter A, et al. Air pollution and subclinical airway inflammation in the salia cohort study. Immun Ageing. 2014;11. doi:10.1186/1742-4933-11-5 
56. Su TC, Hwang JJ, Yang YR, et al. Association between long-term exposure to traffic-related air pollution and inflammatory and thrombotic markers in middle-aged adults. Epidemiology. 2017;28:S74-S81. doi:10.1097/EDE.0000000000000715

57. Shepherd A, Mullins JT. Arthritis diagnosis and early-life exposure to air pollution. Environ Pollut. 2019;253:1030-1037. doi:10.1016/j.envpol.2019.07.054

58. Abohashem S, Osborne MT, Dar T, et al. A leucopoietic-arterial axis underlying the link between ambient air pollution and cardiovascular disease in humans. Eur Heart J. 2021;42:761-772. doi:10.1093/eurheartj/ehaa982

59. Dutta A, Bhattacharya $P$, Lahiri $T$, et al. Immune cells and cardiovascular health in premenopausal women of rural India chronically exposed to biomass smoke during daily household cooking. Sci Tot Environ. 2012;438:293-298. doi:10.1016/j. scitotenv.2012.08.065

60. Hart JE, Laden F, Pueff RC, et al. Exposure to traffic pollution and increased risk of rheumatoid arthritis. Environ Health Perspect. 2009;117:1065-1069. doi:10.1289/ehp.0800503

61. Sigaux J, Biton J, Andre E, et al. Air pollution as a determinant of rheumatoid arthritis. Joint Bone Spine. 2018;86:37-42. doi:10.1016/j.jbspin.2018.03.001

62. Calderon-Garciduenas L, Mora-Tiscareno A, Francolira M, et al. Exposure to urban air pollution and bone health in clinically healthy six-year-old children. Arh Hig Rada Toksikol. 2013;64:23-34. doi:10.2478/10004-1254-64-2013-2219

63. Schett G. Effects of inflammatory and anti-inflammatory cytokines on the bone. Eur J Clin Invest. 2011;41(12):1361-1366. doi:10.1111/j.1365-2362.2011.02545.x

64. Chin K-Y, Wong SK, Ekeuku SO, et al. Relationship between metabolic syndrome and bone health - an evaluation of epidemiological studies and mechanisms involved. Diabetes Metab Syndr Obes. 2020;13:3667-3690. doi:10.2147/DMSO.S275560

65. Ekeuku SO, Pang K-L, Chin K-Y. Effects of caffeic acid and its derivatives on bone: a systematic review. Drug Des Devel Ther. 2021;15:259-275. doi:10.2147/DDDT.S287280

66. Mohd Ramli ES, Sukalingam K, Kamaruzzaman MA, et al. Direct and indirect effect of honey as a functional food against metabolic syndrome and its skeletal complications. Diabetes Metab Syndr Obes. 2021;14:241-256. doi:10.2147/DMSO. S291828

67. Afsar B, Elsurer afsar R, Kanbay A, et al. Air pollution and kidney disease: review of current evidence. Clin Kidney J. 2019;12(1):19-32. doi:10.1093/ckj/sfy111

68. Bowe B, Xie Y, Li T, et al. Associations of ambient coarse particulate matter, nitrogen dioxide, and carbon monoxide with the risk of kidney disease: a cohort study. Lancet Planet Health. 2017;1(7):e267. doi:10.1016/S2542-5196(17)30117-1

69. Bowe B, Xie Y, Li T, et al. Particulate matter air pollution and the risk of incident CKD and progression to esrd. J Am Soc Nephrol. 2018;29(1):218-230. doi:10.1681/ASN.2017030253

70. Xu X, Wang G, Chen N, et al. Long-term exposure to air pollution and increased risk of membranous nephropathy in china. $J$ Am Soc Nephrol. 2016;27(12):3739-3746. doi:10.1681/ ASN.2016010093

71. Wang N, Li M, Huang L, et al. The relationship between pm2.5 and the action spectrum of ultraviolet radiation for vitamin $\mathrm{d}$ production based on a manikin model. IEEE Access. 2020:1.

72. Luo H, Han Y, Lu C, et al. Characteristics of surface solar radiation under different air pollution conditions over Nanjing, China: observation and simulation. Adv Atmos Sci. 2019;36 (10):1047-1059. doi:10.1007/s00376-019-9010-4

73. Liu J, Zhang W. The influence of the environment and clothing on human exposure to ultraviolet light. PLoS One. 2015;10: e0124758. doi:10.1371/journal.pone.0124758
74. Agarwal KS, Mughal MZ, Upadhyay $\mathrm{P}$, et al. The impact of atmospheric pollution on vitamin d status of infants and toddlers in Delhi, India. Arch Dis Child. 2002;87(2):111-113. doi:10.1136/ adc.87.2.111

75. Hosseinpanah F, Pour SH, Heibatollahi M, et al. The effects of air pollution on vitamin d status in healthy women: a cross sectional study. BMC Public Health. 2010;10. doi:10.1186/1471-2458-10519

76. Feizabad E, Hossein-nezhad A, Maghbooli Z, et al. Impact of air pollution on vitamin d deficiency and bone health in adolescents. Arch Osteoporos. 2017;12(1). doi:10.1007/s11657-017-0323-6

77. Matsunawa M, Amano Y, Endo K, et al. The aryl hydrocarbon receptor activator benzo[a]pyrene enhances vitamin $\mathrm{d} 3$ catabolism in macrophages. Toxicol Sci. 2009;109(1):50-58. doi:10.1093/ toxsci/kfp044

78. Moher D, Liberati A, Tetzlaff J, et al. Preferred reporting items for systematic reviews and meta-analyses: the prisma statement. BMJ. 2009;339:b2535. doi:10.1136/bmj.b2535

79. Ma LL, Wang YY, Yang ZH, et al. Methodological quality (risk of bias) assessment tools for primary and secondary medical studies: what are they and which is better? Mil Med Res. 2020;7 (1):7.

80. JBI. Critical appraisal tools; 2020. Available from: https://jbi. global/critical-appraisal-tools. Accessed February 18, 2021.

81. Alvær K, Meyer HE, Falch JA, et al. Outdoor air pollution and bone mineral density in elderly men - the Oslo health study. Osteoporos Int. 2007;18(12):1669-1674. doi:10.1007/s00198007-0424-y

82. Alver K, Meyer HE, Falch JA, et al. Outdoor air pollution, bone density and self-reported forearm fracture: the Oslo health study. Osteoporos Int. 2010;21:1751-1760. doi:10.1007/s00198-0091130-8

83. Cevei M, Stoicanescu D. Air pollution and genetic influences on bone mineral density and osteoporosis. Analele Univ din Oradea Fasc Biol. 2010;Tom. XVII/1:84-89.

84. Lee K-Y, Liu W-T, Kuo HP, et al. Air pollution exposure and osteoporosis among retired workers with chronic obstructive pulmonary disease. Occup Med Health Aff. 2014;2:167.

85. Chen Z, Salam MT, Karim R, et al. Living near a freeway is associated with lower bone mineral density among Mexican americans. Osteoporos Int. 2015;26(6):1713-1721. doi:10.1007/ s00198-015-3051-z

86. Lin $\mathrm{YH}$, Wang $\mathrm{CF}$, Chiu $\mathrm{H}$, et al. Air pollutants interaction and gender difference on bone mineral density t-score in Taiwanese adults. Int $J$ Environ Res Public Health. 2020;17(24):1-15. doi:10.3390/ijerph17249165

87. Qiao D, Pan J, Chen G, et al. Long-term exposure to air pollution might increase prevalence of osteoporosis in Chinese rural population. Environ Res. 2020;183:109264. doi:10.1016/j. envres.2020.109264

88. Ranzani OT, Milà C, Kulkarni B, et al. Association of ambient and household air pollution with bone mineral content among adults in peri-urban south india. JAMA Network Open. 2020;3 (1):e1918504. doi:10.1001/jamanetworkopen.2019.18504

89. Sung JH, Kim K, Cho Y, et al. Association of air pollution with osteoporotic fracture risk among women over 50 years of age. $J$ Bone Miner Metab. 2020;38(6):839-847. doi:10.1007/s00774020-01117-x

90. Mazzucchelli R, Crespi Villarias N, Perez Fernandez E, et al. Short-term association between outdoor air pollution and osteoporotic hip fracture. Osteoporos Int. 2018;29(10):2231-2241. doi:10.1007/s00198-018-4605-7

91. Ormeño Illanes JC, Quevedo Langenegger EI. Air quality and incidence of osteoporotic hip fracture in chile. Rev Osteoporos Metab Miner. 2019;11(4):87-91. doi:10.4321/S1889836X2019000400002 
92. Oh TK, Song IA. Exposure to air pollution and risk of hip fracture: a population-based cohort study with a 6-year followup in south korea. J Occup Environ Med. 2020;62(12):10341039. doi:10.1097/JOM.0000000000002041

93. Prada D, Zhong J, Colicino E, et al. Association of air particulate pollution with bone loss over time and bone fracture risk: analysis of data from two independent studies. Lancet Planet Health. 2017;1(8):e337. doi:10.1016/S2542-5196(17)30136-5

94. Wu HT, Kioumourtzoglou MA, Just AC, et al. Association of ambient pm2.5 exposure with maternal bone strength in pregnant women from mexico city: a longitudinal cohort study. Lancet Planet Health. 2020;4:E530-E537. doi:10.1016/S2542-5196(20)30220-5

95. World Health Organization. Ambient (outdoor) air pollution; 2018. Available from: https://www.who.int/news-room/factsheets/detail/ambient-(outdoor)-air-quality-and-health. Accessed March 20, 2021.

96. Lowther SD, Jones KC, Wang X, et al. Particulate matter measurement indoors: a review of metrics, sensors, needs, and applications. Environ Sci Technol. 2019;53(20):11644-11656. doi:10.1021/acs.est.9b03425

97. Whalley J, Zandi S. Particulate Matter Sampling Techniques and Data Modelling Methods. In: Sallis PJ, editors. Air Quality Measurement and Modeling. London: IntechOpen; 2016:29-54.

98. Wang Q, Zeng Q, Tao J, et al. Estimating pm(2.5) concentrations based on modis aod and naqpms data over Beijing-Tianjin-hebei. Sensors (Basel, Switzerland). 2019;19(5):1207. doi:10.3390/ s19051207

99. Chang $\mathrm{KH}$, Chang MY, Muo $\mathrm{CH}$, et al. Exposure to air pollution increases the risk of osteoporosis: a nationwide longitudinal study. Medicine (United States). 2015;94(17):e733.

100. Azami A, Anari H, Iranparvar M, et al. Comparison of bone mineral densitometry at 2 sites versus 3 sites in patients suspicious for osteoporosis. Clin Med Insights Arthritis Musculoskelet Disord. 2019;12:1179544119849017. doi:10.1177/1179544119849017

101. Mounach A, Mouinga Abayi DA, Ghazi M, et al. Discordance between hip and spine bone mineral density measurement using DXA: prevalence and risk factors. Semin Arthritis Rheum. 2009;38(6):467-471. doi:10.1016/j.semarthrit.2008.04.001

102. Chan CY, Subramaniam S, Mohamed N, et al. Prevalence and factors of t-score discordance between hip and spine among middle-aged and elderly malaysians. Arch Osteoporos. 2020;15 (1):142. doi:10.1007/s11657-020-00821-5

103. Franck H, Munz M. Total body and regional bone mineral densitometry (BMD) and soft tissue measurements: correlations of BMD parameter to lumbar spine and hip. Calcif Tissue Int. 2000;67(2):111-115. doi:10.1007/s00223001124

104. Ott SM. Cortical or trabecular bone: what's the difference? Am J Nephrol. 2018;47(6):373-375. doi:10.1159/000489672

105. Boyanov MA. Whole body and regional bone mineral content and density in women aged 20-75 years. Acta Endocrinol. 2016;12 (2):191-196. doi:10.4183/aeb.2016.191

106. Krieg MA, Barkmann R, Gonnelli S, et al. Quantitative ultrasound in the management of osteoporosis: the 2007 iscd official positions. J Clin Densitom. 2008;11(1):163-187. doi:10.1016/j. jocd.2007.12.011

107. Ekeuku SO, Thong BKS, Quraisiah A, et al. The skeletal effects of short-term triple therapy in a rat model of gastric ulcer induced by helicobacter pylori infection. Drug Des Devel Ther. 2020;14:5359-5366. doi:10.2147/DDDT.S287239
108. Deckard C, Walker A, Hill BJF. Using three-point bending to evaluate tibia bone strength in ovariectomised young mice. J Biol Phys. 2017;43(1):139-148. doi:10.1007/s10867-016-9439-y

109. Arnold M, Zhao S, Ma S, et al. Microindentation - a tool for measuring cortical bone stiffness? Bone Joint Res. 2017;6 (9):542-549. doi:10.1302/2046-3758.69.BJR-2016-0317.R2

110. Zeng X, Liu D, Zhao X, et al. Association of bone mineral density with lung function in a Chinese general population: the Xinxiang rural cohort study. BMC Pulm Med. 2019;19:239. doi:10.1186/ s12890-019-1008-2

111. Mihailov CI, Nelutu MA. Effect of environmental air exposure on rheumatoid arthritis and post-menopausal osteoporosis. J Environ Prot Ecol. 2015;16:340-345.

112. Gärdsell P, Johnell O, Nilsson BE, et al. Bone mass in an urban and a rural population: a comparative, population-based study in southern sweden. J Bone Miner Res. 1991;6(1):67-75. doi:10.1002/jbmr.5650060112

113. Jónsson B, Gärdsell P, Johnell O, et al. Differences in fracture pattern between an urban and a rural population: a comparative population-based study in southern sweden. Osteoporos Int. 1992;2(6):269-273. doi:10.1007/BF01623181

114. Madhok R, Melton LJ 3rd, Atkinson EJ, et al. Urban vs rural increase in hip fracture incidence. Age and sex of 901 cases 1980-89 in Olmsted county, u.S.A. Acta Orthop Scand. 1993;64 (5):543-548. doi:10.3109/17453679308993689

115. Kaastad TS, Meyer HE, Falch JA. Incidence of hip fracture in Oslo, Norway: differences within the city. Bone. 1998;22(2):175178. doi:10.1016/S8756-3282(97)00247-0

116. Sanders KM, Nicholson GC, Ugoni AM, et al. Fracture rates lower in rural than urban communities: the Geelong osteoporosis study. J Epidemiol Community Health. 2002;56(6):466-470. doi:10.1136/jech.56.6.466

117. Meyer HE, Berntsen GK, Sogaard AJ, et al. Higher bone mineral density in rural compared with urban dwellers: the norepos study. Am J Epidemiol. 2004;160(11):1039-1046. doi:10.1093/aje/ kwh337

118. Specker B, Binkley T, Fahrenwald N. Rural versus nonrural differences in BMC, volumetric BMD, and bone size: a population-based cross-sectional study. Bone. 2004;35(6):1389-1398. doi:10.1016/j.bone.2004.09.005

119. Emaus N, Olsen LR, Ahmed LA, et al. Hip fractures in a city in northern Norway over 15 years: time trends, seasonal variation and mortality: the Harstad injury prevention study. Osteoporos Int. 2011;22(10):2603-2610. doi:10.1007/s00198010-1485-X

120. Omsland TK, Ahmed LA, Grønskag A, et al. More forearm fractures among urban than rural women: the norepos study based on the tromsø study and the hunt study. $J$ Bone Miner Res. 2011;26(4):850-856. doi:10.1002/jbmr.280

121. Gu W, Rennie KL, Lin X, et al. Differences in bone mineral status between urban and rural Chinese men and women. Bone. 2007;41 (3):393-399. doi:10.1016/j.bone.2007.05.010

122. Sarmah CK, Bhagawati B. Impact of biomass fuels on health of women and children in rural assam: a statistical study. Indian $J$ Public Health Res Dev. 2014;5(4):163-166. doi:10.5958/09765506.2014.00035.7

123. Fuzzi S, Baltensperger U, Carslaw K, et al. Particulate matter, air quality and climate: lessons learned and future needs. Atmos Chem Phys. 2015;15(14):8217-8299. 


\section{Publish your work in this journal}

Risk Management and Healthcare Policy is an international, peerreviewed, open access journal focusing on all aspects of public health, policy, and preventative measures to promote good health and improve morbidity and mortality in the population. The journal welcomes submitted papers covering original research, basic science, clinical \& epidemiological studies, reviews and evaluations, guidelines, expert opinion and commentary, case reports and extended reports. The manuscript management system is completely online and includes a very quick and fair peer-review system, which is all easy to use. Visit http://www.dovepress.com/testimonials.php to read real quotes from published authors.

Submit your manuscript here: https://www.dovepress.com/risk-management-and-healthcare-policy-journal 